OPEN ACCESS

Edited by:

Alessandro Moura Zagatto, Universidade Estadual Paulista Júlio de Mesquita Filho (UNESP), Brazil

Reviewed by:

Fabio Milioni,

Universidade Estadual Paulista Júlio de Mesquita Filho (UNESP), Brazi Leonardo Alexandre Peyré-Tartaruga, Universidade Federal do Rio Grande do Sul (UFRGS), Brazil

Eduardo Zapaterra Campos, Federal University of Pernambuco,

Brazil

*Correspondence: Fabrice Vercruyssen vercruyssen@univ-tln.fr

Specialty section: This article was submitted to Exercise Physiology, a section of the journal

Frontiers in Physiology

Received: 27 June 2018 Accepted: 29 October 2018 Published: 28 November 2018

Citation:

Ehrstrom S, Gruet M, Giandolini M, Chapuis S, Morin J-B and Vercruyssen F (2018) Acute and Delayed Neuromuscular Alterations Induced by Downhill Running in Trained Trail Runners: Beneficial Effects of High-Pressure

Compression Garments.

Front. Physiol. 9:1627. doi: 10.3389/fphys.2018.01627

\section{Acute and Delayed Neuromuscular Alterations Induced by Downhill Running in Trained Trail Runners: Beneficial Effects of High-Pressure Compression Garments}

\author{
Sabine Ehrstrom ${ }^{1}$, Mathieu Gruet ${ }^{2}$, Marléne Giandolini ${ }^{3}$, Serge Chapuis ${ }^{4}$, \\ Jean-Benoit Morin ${ }^{1}$ and Fabrice Vercruyssen ${ }^{2 *}$
}

\begin{abstract}
${ }^{1}$ Université Côte d'Azur, LAMHESS, Nice, France, ${ }^{2}$ Université de Toulon, LAMHESS, Toulon, France, ${ }^{3}$ Amer Sports Footwear Innovation and Sport Sciences Lab, Salomon SAS, Annecy, France, ${ }^{4}$ Amer Sports Gear and Apparel Innovation and Sport Sciences Lab, Salomon SAS, Annecy, France
\end{abstract}

Introduction: The aim of this study was to examine, from a crossover experimental design, whether wearing high-pressure compression garments (CGs) during downhill treadmill running affects soft-tissue vibrations, acute and delayed responses in running economy (RE), neuromuscular function, countermovement jump, and perceived muscle soreness.

Methods: Thirteen male trail runners habituated to regular eccentric training performed two separate $40-$ min downhill running (DHR, $\left.-8.5^{\circ}\right)$ sessions while wearing either CGs (15-20 mmHg for quadriceps and calves) or control garments (CON) at a velocity associated with $\sim 55 \%$ of $\mathrm{VO}_{2 m a x}$, with a set of measurements before (Pre-), after (PostDHR), and 1 day after (Post-1D). No CGs was used within the recovery phase. Perceived muscle soreness, countermovement jump, and neuromuscular function (central and peripheral components) of knee extensors (KE) and plantar flexors (PF) were assessed. Cardiorespiratory responses (e.g., heart rate, ventilation) and RE, as well as soft-tissue vibrations (root mean square of the resultant acceleration, RMS $A_{r}$ ) for vastus lateralis and gastrocnemius medialis were evaluated during DHR and in Post-1D.

Results: During DHR, mean values in RMS $A_{r}$ significantly increased over time for the vastus lateralis only for the CON condition (+11.6\%). RE and cardiorespiratory responses significantly increased (i.e., alteration) over time in both conditions. Post-DHR small to very large central and peripheral alterations were found for KE and $\mathrm{PF}$ in both conditions. However, the deficit in voluntary activation (VA) was significantly lower for KE following CGs (-2.4\%), compared to CON (-7.9\%) conditions. No significant differences in perceived muscle soreness and countermovement jump were observed between conditions whatever the time period. Additionally, in Post-1D, the CGs condition showed reductions in neuromuscular peripheral alterations only for KE (from -4.4 to $7.7 \%)$ and perceived muscle soreness scores (-8.3\%). No significant differences in 
cardiorespiratory and RE responses as well as countermovement jump were identified between conditions in Post-1D.

\begin{abstract}
Discussion: Wearing high-pressure CGs (notably on KE) during DHR was associated with beneficial effects on soft-tissue vibrations, acute and delayed neuromuscular function, and perceived muscle soreness. The use of CGs during DHR might contribute to the enhanced muscle recovery by exerting an exercise-induced "mechanical protective effect."
\end{abstract}

Keywords: compression garments, soft-tissue vibrations, muscle fatigue, running economy, muscle damage, downhill running

\section{INTRODUCTION}

Trail running is characterized by the succession of long uphill and downhill sections in a natural environment (for review, see Giandolini et al., 2016b). In trail running races where the distance may vary from short $(<42 \mathrm{~km})$ to ultra-long $(\geq 100 \mathrm{~km})$, severe alterations in neuromuscular function were reported with substantial failures in both central and peripheral neuromuscular mechanisms for knee extensors (KE) and plantar flexors (PF) (Millet et al., 2003, 2011b; Easthope et al., 2010; Saugy et al., 2013). In these studies, peripheral muscle fatigue may be greatly associated with exercise-induced muscle damage (EIMD) over repeated and prolonged eccentric muscle actions through downhill sections. Intense and/or prolonged downhill running (DHR) is well known to induce a substantial peripheral fatigue and/or low-frequency fatigue in lower limb muscles, assessed from reduced $\mathrm{M}$-waves amplitudes and a decrease in the ratio between force evoked by low-frequency stimulation (e.g., $10-20 \mathrm{~Hz}$ ) and force evoked by high-frequency stimulation (50$100 \mathrm{~Hz}$ ) (Martin et al., 2004; Giandolini et al., 2016a). Cellular mechanisms underpinning peripheral fatigue may be attributed to longer muscle lengths (i.e., overstretched sarcomeres) during eccentric muscle actions over braking phases, leading to myofibrillar damage such as disrupted weaker sarcomeres and/or excitation-contraction coupling failure (Proske and Morgan, 2001; Douglas et al., 2017). Although the contribution of central component to neuromuscular fatigue is less important during DHR, central fatigue assessed by a decline in maximal voluntary activation (VA) (2.5-8.0\%) was found for KE and PF following a 30-min treadmill DHR (-20\%) and a $6.5 \mathrm{~km}$ downhill trail run ( -16\%) (Giandolini et al., 2016a; Martin et al., 2004). This central fatigue could originate from supra-spinal level or from inhibitory reflexes mediated by free endings of group III and IV afferents, stimulated by metabolites and damage to muscle spindles (Martin et al., 2005).

From a biomechanical perspective, foot-ground impacts cause sudden decelerations of soft-tissue packages inducing muscle oscillations. According to the "muscle tuning" paradigm, muscle activity is tuned in response to impact forces to dampen softtissue vibrations (Wakeling et al., 2001). During DHR, substantial increases in vertical impact force peaks $(>50 \%)$ and horizontal braking force peaks $(>70 \%)$ at steep slopes (i.e., $-9^{\circ}$ ) were observed, compared to level running (Gottschall and Kram, 2005). Regarding the knee and ankle joints, which are considered as net absorbers and generators of force during DHR, the negative work period as a percentage of total stance time is significantly greater for these two joints during DHR than level running sessions (Eston et al., 1995). This longer negative work period combined with a reduced upward displacement of the center of mass causes a gradual disappearance of the bouncing mechanism during DHR as speed and slope become greater (Dewolf et al., 2016). Consequently, the negative work done by both $\mathrm{KE}$ and PF muscles is about twofold greater during DHR with a $-8.3 \%$ slope than during level running as the same speed $\left(4.5 \mathrm{~m} . \mathrm{s}^{-1}\right)$ (Buczek and Cavanagh, 1990). Therefore, $\mathrm{KE}$ or PF fatigue is greater after DHR than level running as a consequence of important absorption function and increased electromyographic activities (Giandolini et al., 2016a, 2017; Maeo et al., 2017). As a matter of fact, the increase in vertical downward velocity associated with higher ground reaction forces experienced during DHR might accentuate soft-tissue vibrations (Dewolf et al., 2016) and in turn, muscle activity. For instance, triceps surae soft tissue vibrations increased during prolonged and intense running sessions (Friesenbichler et al., 2011; Khassetarash et al., 2015). Since these findings were obtained during level treadmill running $(\sim 40 \mathrm{~min})$ at a relatively low velocity (from 3 to $4 \mathrm{~m} . \mathrm{s}^{-1}$ ), one could assume that prolonged exposures of KE and PF to higher loading rate induced by a strenuous DHR may cause greater soft-tissue vibrations and in turn, increased electromyographic activity, which might contribute to greater EIMD and muscle fatigue.

On the physiological side, muscle fatigue may be associated with acute and delayed alterations in running economy (RE), i.e., oxygen demand for a given running speed, following trail running events (Vernillo et al., 2017) or laboratory-based DHR sessions (Chen et al., 2007). In a recent review, Vernillo et al. (2017) have suggested that muscle fatigue needs to be compensated by a greater neural input to the active muscles to produce the same amount of force, particularly during the push-off phase of the running step, leading to an altered RE (Vernillo et al., 2017). Interestingly, following a 65-km mountain ultramarathon, RE was significantly altered during downhill treadmill running whereas no significant changes in either level or uphill RE were observed. These results suggest that different contraction regimens specifically affect RE during exercise (Vernillo et al., 2015). It was also described that repeated and prolonged muscle eccentric actions induced by a 30-min treadmill DHR durably affect level RE at high metabolic 
intensities $\left(>70 \% \mathrm{VO}_{2 \max }\right)$ in the recovery phase (up to 5 days after DHR) in untrained and moderately trained subjects (Chen et al., 2007, 2009).

Several strategies including DHR training sessions and the use of lower limb compression garments (CGs) have been tested in an attempt to reduce RE alterations and detrimental effects of muscle damage and/or muscle fatigue induced by trail running or DHR events (Bieuzen et al., 2014; Hill et al., 2014; Peake et al., 2017; Toyomura et al., 2017; Vercruyssen et al., 2017). Although recent reviews and meta-analyses indicated that wearing CGs during recovery may be effective in the attenuation of EIMD (Beliard et al., 2014; Hill et al., 2014; Brown et al., 2017), the beneficial effects of CGs on acute physiological responses during running are still debated.

In this regard, MacRae et al. (2011) reported that discrepancies in the findings might be population- and exercise-dependent (e.g., training status, treadmill slopes) or related to CGs features (e.g., intensity of compression). Using magnetic resonance imaging, Miyamoto and Kawakami (2014) found that wearing short tights with a high-pressure intensity of 15-20 $\mathrm{mmHg}$ reduced muscle fatigue during treadmill running. Additionally, a reduction in $\mathrm{KE}$ force decline was identified following a $15.6 \mathrm{~km}$ short trail running only for subjects wearing highpressure compression stockings $(>15 \mathrm{mmHg}$ ) during exercise (Bieuzen et al., 2014). The use of high-pressure CGs (>15 mmHg) might thus induce a beneficial effect on muscle damage during exercise and potentially, on RE. Investigations with participants not accustomed to DHR showed that the use of CGs may be an effective method to reduce muscle damage induced by DHR (Valle et al., 2013), by attenuating soft-tissue vibrations during exercise (Bieuzen et al., 2014). However, this mechanistic hypothesis has never been validated during eccentric endurance exercises either in recreational subjects or trained runners. The interest of wearing CGs in trail runners habituated to DHR, and for whom adaptations due to the repeated bout effects have already been induced by eccentric training (Hyldahl et al., 2017), remains to be elucidated. Therefore, it seems important to assess the effectiveness of wearing high-pressure CGs during DHR within a homogeneous group of well-trained trail runners habituated to eccentric contractions, through several outcome measurements including soft-tissue vibrations, RE, neuromuscular function, countermovement jump performance, and perceived muscle soreness.

Accordingly, the objective of the current work was to examine the effects of wearing high-pressure CGs (>15 $\mathrm{mmHg}$ ) during a 40-min treadmill DHR on acute and delayed neuromuscular responses and $\mathrm{RE}$ in well-trained trail runners accustomed to eccentric work. We hypothesized that wearing CGs during exercise would reduce soft-tissue vibrations and thus, acute and delayed central and peripheral fatigue and improve RE.

\section{MATERIALS AND METHODS}

\section{Subjects}

Thirteen well-trained male trail runners $[($ mean \pm SD) age: $38.6 \pm 5.7$ years; height: $175.8 \pm 5.1 \mathrm{~cm}$; body mass:
$72.1 \pm 4.7 \mathrm{~kg}$ ] participated to this study. Participants had a mean of $8.8 \pm 3.4$ years of trail running practice and were regularly involved in short-distance races $(20-45 \mathrm{~km})$. The average weekly training mileage during the two weeks before the first laboratory visit was $51.0 \pm 20.6 \mathrm{~km}$ including $1913 \pm 1181 \mathrm{~m}$ of positive/negative elevation. The sample size was calculated according to a previous study by Bieuzen et al. (2014) investigating the effect of a short trail running exercise [model inducing similar decrements in maximal voluntary contractions (MVC) than DHR] with the use of different running apparels on acute and delayed muscle fatigue (i.e., decline in MVC over time considered as the primary outcome), with a statistical power of $80 \%$ and a significance at $P \leq 0.05$. Their mean $\mathrm{VO}_{2 \max }$ and maximal heart rate $\left(\mathrm{HR}_{\max }\right)$ were $64.6 \pm 5.0 \mathrm{ml} \cdot \mathrm{kg}^{-1} \cdot \mathrm{min}^{-1}$ and $183.1 \pm 8.1$ beats. $\mathrm{min}^{-1}$, respectively. All subjects had previous experience with CGs for at least 2 years but none of them wore CGs on a regular basis during racing. This study was carried out in accordance with the recommendations of local institutional review committee (University of Toulon) with written informed consent from all subjects. All subjects gave written informed consent in accordance with the Declaration of Helsinki. The protocol was approved by the local institutional review committee (University of Toulon).

\section{Experimental Design}

Participants visited the laboratory on five different occasions. During the first visit, subjects performed a maximal test on a motorized treadmill (Venus ${ }^{\circledR} 200 / 100$ r, HP $\operatorname{cosmos}^{\circledR}$, Germany) with a $10 \%$ slope that aimed at determining $\mathrm{VO}_{2 \max }$ and $\mathrm{HR}_{\text {max }}$. During this test, $\mathrm{HR}$ and breath-by-breath $\mathrm{VO}_{2}$ values were averaged every $10 \mathrm{~s}$ by the Oxycon Alpha metabolic measurement cart (Jaeger ${ }^{\circledR}$, Germany). $\mathrm{VO}_{2 \max }$ was determined from the three highest consecutive values (i.e., over a 30-s interval) reached during the last stage of the protocol. Following a 30-min recovery period which enabled to return to baseline $\mathrm{VO}_{2}$ and $\mathrm{HR}$ values (i.e., before the $\mathrm{VO}_{2 \max }$ protocol), subjects were instructed to run on the treadmill for the determination of velocity associated with $55 \% \mathrm{VO}_{2 \max }$ of DHR (i.e., $V_{D H R},-8.5^{\circ}$ ). In this session, subjects were familiarized with all experimental procedures. During the second and the fourth visits (separated by one week), athletes performed one 40-min treadmill DHR while wearing different running garments, with a set of measurements immediately before (Pre-) and after (Post-DHR). Each DHR session was followed by a similar set of measurements 1 day after (Post-1D, i.e., third and fifth visits) to evaluate the delayed effects of DHR (Figure 1). These blocks of 2 days (i.e., DHR + Post-1D) were performed in a counterbalanced and randomized order ${ }^{1}$.

Before starting DHR or Post-1D, subjects first carried out a warm-up which consisted of 7 min of level running $\left(3.05 \mathrm{~m} . \mathrm{s}^{-1}\right)$ and $3 \mathrm{~min}$ of DHR $\left(3.33 \mathrm{~m} . \mathrm{s}^{-1} ;-10 \%\right.$ slope $)$. Then, perceived muscle soreness, countermovement jump, and neuromuscular function were evaluated in this order. During this set of measurements, subjects were asked to wear control garments (CON condition, loose-fitting conventional running garments, compression intensity $<5 \mathrm{mmHg}$ ), whatever the running apparel

\footnotetext{
${ }^{1}$ www.randomizer.org
} 
assigned to DHR. After the neuromuscular protocol, subjects kept CON garments or wore lower limb CGs (CGs condition, SALOMON ${ }^{\circledR}$ S/LAB EXO garments, stocking with $20-25$ mmHg at the middle of calf and $18-20 \mathrm{mmHg}$ at the upper site of calf, short-thigh with 16-18 $\mathrm{mmHg}$ at the middle of thigh, and 18$20 \mathrm{mmHg}$ at the lower site of thigh) to begin DHR sessions. No "in vivo" CGs measurements (i.e., using a pressure sensor) were performed in our subjects during the DHR sessions. Prior to laboratory running sessions, CGs were re-fitted to obtain the required range of compression level according to manufacturer's guidelines and based on subject's circumference (i.e., upper, middle, and lower sites of thigh; middle and upper sites of calf) and limb lengths (Vercruyssen et al., 2017).

Running economy, HR, ventilation $\left(V_{E}\right)$, respiratory exchange ratio (RER), and step frequency $(f)$ were determined at different time periods of DHR conditions but also, at $V_{D H R}\left(-8.5^{\circ}\right)$ during the Post-1D run bouts. Accelerations of soft-tissue packages were exclusively measured during DHR conditions, allowing to assess soft-tissue vibrations at different time periods. At the end of each DHR, subjects were asked to report perceived muscle soreness scores and took off their CGs (for subjects wearing them during DHR) to complete a pair of countermovement jumps. No CGs were used during the set of measurements after DHR and within the recovery phase. The order of measurements in Post-1D was standardized as follows: perceived muscle soreness, countermovement jumps, neuromuscular function, and RE during the 5-min running bout at $V_{D H R}$ (Figure 1). Between the end of each DHR and the beginning of Post-1D testing bouts, participants were instructed not to perform any interventions including massage, icing and nutritional strategies (e.g., protein intake) possibly affecting the recovery process. Each subject received an isotonic carbohydrate $(\mathrm{CHO})$-sports drink $(600 \mathrm{ml})$ after DHR and the quantity of $\mathrm{CHO}$ feedings was standardized (i.e., 8-10 g CHO per $\mathrm{kg}$ body mass) during the recovery phase. The training program was also standardized during the 7-day washout period separating the two exercise blocks (i.e., a 1-day passive rest between the end of DHR and Post-1D sessions for a given block but also, before the second DHR block, with intermediate sessions of 60-min swimming and 40min low-intensity flat running at a mean $\mathrm{HR}<75 \% \mathrm{HR}_{\text {max }}$ ). All experimental sessions were performed at the same time of day for a given subject and conducted between 10:00 and 16:00 hours under similar laboratory conditions $\left(18-20^{\circ} \mathrm{C}, 35-40 \%\right.$ relative humidity).

\section{Downhill Running}

Following $3 \mathrm{~min}$ of high-intensity level running (i.e., corresponding to $3.88 \mathrm{~m} . \mathrm{s}^{-1}$ ), the treadmill slope was immediately set to a $-8.5^{\circ}$ and $V_{D H R}$ was also set to induce the equivalent of a metabolic intensity of $55 \% \mathrm{VO}_{2 \max }$. Then, the treadmill velocity was not changed within and between DHR exercises. Based on various pilot testing, $V_{D H R}$ was considered as a severe intensity which could be mechanically tolerated (in terms of repeated braking forces) by subjects during a 40-min period. According to Chen et al. (2009) and the reality of trail running, the gradient was set at $-8.5^{\circ}$ to induce substantial mechanical impairments. Mean $V_{D H R}$ represented $4.20 \pm 0.23 \mathrm{~m} . \mathrm{s}^{-1}$ during the DHR conditions and the Post-1D run bouts $\left(-8.5^{\circ}\right)$. During the DHR conditions, mean $\mathrm{VO}_{2}$ were $35.7 \pm 3.5 \mathrm{ml} . \mathrm{min}^{-1} . \mathrm{kg}^{-1}$ for CON (i.e., $54.3 \pm 4.6 \% \mathrm{VO}_{2 \max }$ ) and $36.4 \pm 2.0 \mathrm{ml} . \mathrm{min}^{-1} . \mathrm{kg}^{-1}$ for CGs (i.e., $55.5 \pm 2.9 \% \mathrm{VO}_{2 \max }$ ).

\section{Neuromuscular Function}

The neuromuscular function was tested using the method of electrical stimulation as recommended by Millet et al. (2011a) similarly on the right KE and PF muscles in Pre, Post-DHR (7 min and 10-min after exercise termination for $\mathrm{KF}$ and/or PF), and Post-1D (same order of measurements than in Post for KF and $\mathrm{PF}$ ). The evaluation of neuromuscular function was randomized for $\mathrm{KE}$ and PF in Post-DHR for a given condition. Before each test, the optimal stimulation intensity was identified by delivering successive single electrical stimuli at increasing intensities on relaxed muscles on the femoral (for $\mathrm{KE}$ ) and tibial (for $\mathrm{PF}$ ) nerves. The stimulation intensity used during all tests was $130 \%$ of optimal intensity to ascertain full spatial recruitment. The optimal stimulation intensities ranged from 110 to $160 \mathrm{~mA}$ for $\mathrm{KE}$ and from 110 to $130 \mathrm{~mA}$ for PF through the Pre-, Post-DHR, and Post-1D sessions. For the KE testing, subjects seated upright in a custom-built chair with hips at $100^{\circ}$ of flexion and knees at $90^{\circ}$. The subjects' ankle was strapped by non-compliant straps to the calibrated force transducer (F 501 TC 200 daN, TME 78 Orgeval, France) located slightly above the malleoli. The subjects were firmly attached to the ergometer with a rally car harness to avoid lateral and frontal displacements and were instructed to grip the harness during the test to standardize arm placement. For PF testing, subjects seated in the same custom-built chair and placed their foot, in a $0^{\circ}$ dorsiflexion position, on a customized ergometer equipped with an instrumented pedal (SMTR $500 \mathrm{Nm}$, Sensel Measurement, Vincennes, France) located in the chair alignment. The forefoot was strapped to the pedal to limit heel lift and subjects were asked to perform a plantar flexion while keeping arms on their chest. The strain gauge and the pedal force were used to record the mechanical responses during MVC and electrically evoked contractions.

During the neuromuscular tests, transcutaneous electrical stimulations were applied to the femoral and posterior tibial nerves via a self-adhesive electrode cathode (10 $\mathrm{mm}$ in diameter) pressed manually by a researcher into either the femoral triangle (for KE) or the popliteal fossa (for PF) (Jubeau et al., 2017). The self-adhesive rectangular anode $(50 \mathrm{~mm} \times 90 \mathrm{~mm}$, Dura-Stick Premium, Compex) was located either in the gluteal fold (for KE), or on the patella (for PF). A constant current stimulator (model DS7A, Digitimer, Hertfordshire, United Kingdom) delivered a square wave stimulus of $1 \mathrm{~ms}$ duration and $400 \mathrm{~V}$ maximal voltage and the interval of stimuli in the doublet were 100 and $10 \mathrm{~ms}$ for doublets at $10 \mathrm{~Hz}\left(\mathrm{Db}_{10}\right)$ and $100 \mathrm{~Hz}\left(\mathrm{Db}_{100}\right)$, respectively. Surface EMG signals were continuously recorded from the vastus lateralis and the gastrocnemius medialis muscles with a pair of self-adhesive surface (10 $\mathrm{mm}$ diameter) electrodes (Controle Graphique Medical, Brie-Comte-Robert, France) in bipolar configuration with a $20-\mathrm{mm}$ interelectrode distance. The reference electrode was attached on the patella. Signals were amplified with a bandwidth frequency ranging from $1 \mathrm{~Hz}$ to $5 \mathrm{kHz}$ (common mode rejection ratio $=110 \mathrm{~dB}$, impedance 


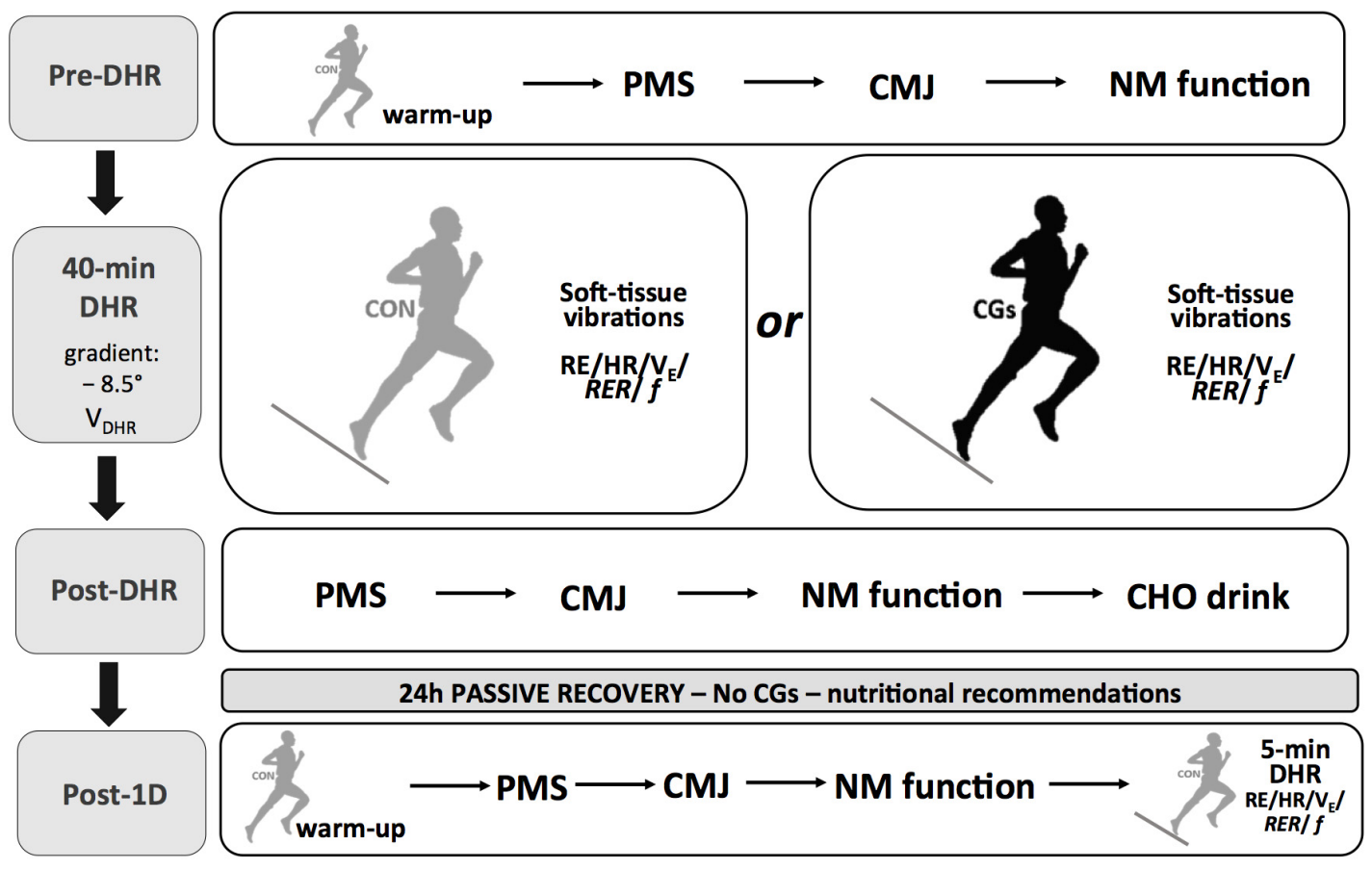

FIGURE 1 | Schematic representation of the experimental design. Abbreviations: CON, control garments; CGs, compression garments; DHR, downhill running; $V_{D H R}$, velocity associated with $55 \% \mathrm{VO}_{2 m a x}$; PMS, perceived muscle soreness; CMJ, countermovement jump; NM function, neuromuscular function; RE, running economy; HR, heart rate; $V_{E}$, ventilation; RER, respiratory exchange ratio; $f$, step frequency.

input $=1000 \mathrm{M} \Omega$, gain $=1000$ ), digitized online at a sampling rate of $2000 \mathrm{~Hz}$ and stored for analysis with commercially available software (Acqknowledge 4.1, Biopac Systems Inc.).

For each condition, neuromuscular evaluation was conducted twice in Pre-, Post-DHR, and Post-1D. After a specific KE or $\mathrm{PF}$ isometric warm-up in both Pre- and Post-1D (i.e., 3-min submaximal contractions performed at increasing force levels), participants performed a similar neuromuscular evaluation for KE and PF which first consisted of a 4-s MVC followed by two single potentiated twitches separated by $2 \mathrm{~s}$ on the relaxed muscles. This procedure was repeated a second time after $15 \mathrm{~s}$ of rest. Following a resting period of $30 \mathrm{~s}$, the subjects performed a third 4-s MVC superimposed with Db100 and followed after $2 \mathrm{~s}$ by two potentiated doublets in the relaxed muscle, i.e., Db100 and Db10, delivered $2 \mathrm{~s}$ apart. After $15 \mathrm{~s}$ of rest, this procedure was repeated a second time. The amplitude of the potentiated Db10, $\mathrm{Db} 100$, and the amplitude of the potentiated twitch peak torque $\left(T_{W}\right)$ that followed the two doublets as well as the ratio of paired stimulation peak forces at $10 \mathrm{~Hz}$ over $100 \mathrm{~Hz}$ (Db10:100) were analyzed for both KE and PF. Throughout the testing sessions, subjects were strongly encouraged during their MVC. On the contrary, they were asked to be as relaxed as possible during the peripheral fatigue measurements. For each variable, values were then averaged from the two series in Pre-, Post-DHR, and Post-1D.

The variability in VA was determined to assess central fatigue for $\mathrm{KE}$ and $\mathrm{PF}$ using a high-frequency doublet $(100 \mathrm{~Hz})$ superimposed on MVC. VA was calculated from the maximal force $\left(F_{\max }\right)$ attained during the MVC, the force just before the superimposed doublet $\left(F_{\text {before }}\right)$, the peak force following the superimposed doublet (Db100 sup $)$, and control Db100 on relaxed muscle (Giandolini et al., 2016a) as follows:

$$
\mathrm{VA}=\left[1-\frac{\left(\mathrm{Db} 100_{\text {sup }}-F_{\text {before }}\right) \times \frac{F_{\text {before }}}{F_{\max }}}{\text { control Db100 }}\right] \times 100 .
$$

\section{Running Economy and Cardiorespiratory Parameters}

Breath-by-breath $\mathrm{VO}_{2}$ values, $V_{E}$, and RER were averaged every $10 \mathrm{~s}$ by the metabolic cart during overall DHR and Post-1D run sessions. For analysis, $\mathrm{RE}$ (expressed as $\mathrm{VO}_{2}$ for a given running velocity, in $\left.\mathrm{mlO}_{2} \cdot \mathrm{min}^{-1} \cdot \mathrm{kg}^{-1}\right), V_{E}$, and RER were averaged values from two time periods at the beginning (3-5 and 8$10 \mathrm{~min}$ ) and the end of DHR (33-35 and 38-40 $\mathrm{min}$ ) but also, during the 5-min running bout at $V_{D H R}(3-5 \mathrm{~min}$ ) in Post 1-D. Using the HR sensor of the metabolic cart, HR values were also determined during the same time periods.

\section{Running Mechanics}

Stride frequency was determined during the same time periods than for the RE measurements during DHR and in Post-1D (see above) using the app Runmatic recently validated (BalsalobreFernández et al., 2016) and installed on an iPhone 6 running iOS 11.0.3 (240 Hz high-speed camera, Apple Inc., Cupertino, CA, United States). To record the step periods, one operator 
lay prone on the ground, $30 \mathrm{~cm}$ from the back of the treadmill (e.g., to analyze the back of the subjects' feet), and held the iPhone in a vertical position at the same level as the floor of the treadmill. Then, contact time $\left(t_{c}\right)$ was calculated as the time between the first frame in which the foot contacts the treadmill and the first frame in which the foot takes off. Aerial time $\left(t_{a}\right)$ was calculated as the time between the first frame in which the foot takes off from treadmill and the first frame in which the other foot makes contact with the treadmill. Finally, $t_{c}$ and $t_{a}$ (in s) were averaged throughout eight consecutive steps (i.e., four stride cycles) and used to calculate step frequency $(f$, in $\mathrm{Hz})$. The standard errors of estimate of the app Runmatic, compared to an opto-electronic device (Optojump Next) were $0.0056 \mathrm{~s}$ for contact time and $0.0048 \mathrm{~s}$ for aerial time.

\section{Soft-Tissue Vibrations}

The current accelerometry method for quantifying soft-tissue vibrations has been previously validated in the context of running (Coza et al., 2010). Two lightweight tri-axial accelerometers (range $= \pm 200 \mathrm{~g}$, mass $= \pm 5 \mathrm{~g}$, TSD109, Biopac Systems, Inc., Goleta, CA, United States) were placed on the skin under the CON garments and CGs at the muscle belly of the vastus lateralis and gastrocnemius medialis of the right leg to quantify soft-tissue vibrations. Accelerometers were placed under CGs to maintain the permanent contact between the sites of skin and accelerometers. Accelerometers were attached using a doublesided adhesive and slightly plated with an adhesive tape to improve congruence with soft tissues without altering their motion. Their location was marked with indelible ink on the skin to enable reproducible accelerometer placement withinand between conditions. Acceleration signals were sampled at $1000 \mathrm{~Hz}$, recorded for a 30-s interval at different time intervals of DHR and subsequently analyzed in Scilab 5.5.2 software (Scilab Enterprises, Orsay, France). To quantify the amount of soft-tissue vibrations, a time domain analysis was performed over the overall signals including both the stance and flight phases. The resultant acceleration $\left(A_{r}\right)$ was calculated from the three acceleration components for each muscle. The root mean square of the $A_{r}$ values (i.e., RMS $A_{r}$ ) was then calculated and averaged using a 10 -ms time window. For analysis, RMS $A_{r}$ for each muscle was finally averaged from two time periods at the beginning (4-5 and 9-10 $\mathrm{min}$ ) and the end of DHR (34-35 and 39-40 $\mathrm{min}$ ) to characterize the time effect on RMS $A_{r}$ within-and-between DHR sessions.

\section{Perceived Muscle Soreness}

According to previous studies (Chen et al., 2009), perceived muscle soreness scores were assessed in Pre, Post-DHR, and Post$1 \mathrm{D}$ sessions, using a visual analogue scale consisting of a $100-\mathrm{mm}$ continuous line anchored by "no pain" $(0 \mathrm{~mm})$ and "very, very painful" (100 mm). Subjects were asked to report the severity of global muscle soreness concerning the quadriceps and calves immediately after performing a five repetition sit-stand motion on each occasion.

\section{Countermovement Jump Performance}

All participants were familiarized with countermovement jump testing during the first visit and completed countermovement jumps with hands on their hips, starting from a static position. Then, subjects performed a countermovement downward immediately followed by a complete extension of the lower limbs. During the flight phase of the jump, participants were instructed to jump as high as possible, and take-off and land with the feet simultaneously contacting the ground with the ankle in full dorsiflexion. The countermovement jump height was calculated using the app My Jump recently developed and validated by (Balsalobre-fernández et al., 2015). This app was installed on the same iPhone 6 used for the running mechanics recordings. To monitor the countermovement jump with My Jump, the device was installed onto the ground facing the subject's feet (at $\sim 1.5 \mathrm{~m}$ ). Take-off and landing frames of the video were used by the app for the calculation of the flight time and in turn countermovement jump height. Each athlete performed two countermovement jumps, separated by a 1-min passive rest period, in Pre (after a 10-min run warm-up), Post-DHR, and Post-1D sessions. The two countermovement jumps values were averaged for further statistical analysis. When compared to a force platform, Balsalobre-fernández et al. (2015) showed that a good reliability of the app for jump heights performed by different subjects (observer 1: $\alpha=0.997, \mathrm{CV}=3.4 \%$; observer 2: $\alpha=0.988, \mathrm{CV}=3.6 \%)$. Furthermore, the Pearson product moment correlation coefficient showed almost perfect correlation between the app and the force platform measurements for jump height $(r=0.995, P<0.001)$.

\section{Statistical Analysis}

All dependent variables among CON and CGs exercises over the DHR/Post-1D blocks were initially tested for the normality of distribution and the homogeneity of variances using ShapiroWilk and Levene tests. Separate two-way ANOVAs (condition [CON, CGs] $\times$ time [Pre, Post, or Post-1D] and time periods over DHR) with repeated measures were applied to all dependent variables. This allowed quantification of the acute (Pre-Post) and delayed (Pre-Post 1-D) fatigue induced by DHR on dependent variables. When significant main effects were observed, Bonferroni's test was used for post-hoc analysis. Withinand between exercise differences were also standardized from the use of Cohen's effect sizes (ES) and thresholds [>0.2 (small), $>0.6$ (moderate), $>1.2$ (large), and $>2.0$ (very large)] associated with $90 \%$ confidence limits (CL) to compare the magnitude of the difference of the change between pre- and post-DHR (immediate and post-1D) (Hopkins et al., 2009; Bieuzen et al., 2014). Probabilities that differences were higher, lower or similar to the smallest worthwhile difference (ES of 0.20 ) were evaluated qualitatively as follows: possibly, 25-74.9\%; likely, 75-94.9\%, very likely, 95-99.5\%; most (extremely) likely, $>99.5 \%$. The true difference was assessed as unclear if the chance of both higher and lower values was >5\% (Hopkins et al., 2009; Buchheit, 2016). The null hypothesis significance testing (NHST) was the primary method to discuss the current results and the qualitative approach (e.g., Cohen's ES and smallest worthwhile changes) was 
used to further illustrate the differences between CON and CGs conditions, particularly when one clothing modality induced a significant effect over time. For all tests, an alpha of $P<0.05$ was considered statistically significant. All qualitative analyses were conducted using modified statistical Excel spreadsheets. ${ }^{2}$

\section{RESULTS}

All participants successfully completed the two blocks of DHRPost-1D sessions, excepted for one subject where PF MVC values could not be analyzed for technical reasons. All standardized effects are presented as ES $\pm 90 \%$ CL. In order to ensure the CGs or CON conditions were performed in a comparable physical state, MVC for KE and PF but also, body mass were selected as standardization variables across exercises (in Pre-DHR). No significant differences were observed between conditions for the MVC responses for $\mathrm{KE}(P=0.08)$ and $\mathrm{PF}(P=1.00)$ or body mass $(P=1.00)$.

\section{Neuromuscular Function}

The changes in neuromuscular responses within-and-between exercise blocks are presented in Table $\mathbf{1}$ (i.e., Pre/Post-DHR) and Table 2 (i.e., Pre-DHR/Post-1D). Small to very large alterations (i.e., significant decreases) in acute neuromuscular responses, excepted for VL and GAST M-waves but also, for PF Db10:100, were found for both CON and CGs conditions, whatever the studied muscle (Table 1). A significant time $\times$ condition interaction was identified immediately after DHR for the KE VA deficit $(P=0.022)$. The KE VA deficit was significantly higher after CON than CGs, with a "moderate" standardized difference $(\mathrm{ES}=0.83 \pm 0.76$, Table 1). The PF VA deficit significantly increased in the CON condition $(P=0.022)$, whereas no significant change in this variable was observed in the CGs condition $(P=0.398)$. Substantial delayed effects were also identified on neuromuscular responses for KE after CON condition while minor delayed effects were reported following CGs condition (Table 2). A significant time $\times$ condition interaction was found for decrements in $\operatorname{KE~MVC~}(P=0.033)$, $\mathrm{KE} \mathrm{Db10}(P=0.035)$, and $\mathrm{KE} \mathrm{Db10:100}(P=0.042)$ which were significantly lower at 24-h after CGs condition, compared to CON condition. These differences in delayed neuromuscular responses were not reported for $\mathrm{PF}$, excepted for $T_{w}$ values that were significantly lower following CON condition $(P=0.036)$. Given that the most beneficial effects of CGs were observed in Post-1D, the magnitude of Pre-DHR/Post-1D changes for all neuromuscular variables is presented in Figure 2. In addition, individual MVC responses for $\mathrm{KE}$ and $\mathrm{PF}$ across the two exercise blocks are displayed in Figure 3.

\section{Soft-Tissue Vibrations}

Figure 4A shows changes in RMS $A_{r}$ over time for vastus lateralis and gastrocnemius medialis within CON and CGs conditions. A significant increase in RMS $A_{r}$ was observed over time for the vastus lateralis in the $\mathrm{CON}$ condition

${ }^{2}$ www.sportsci.org
$(+11.6 \pm 5.9 \% ; \mathrm{ES}=0.69 \pm 0.24 ; P=0.003)$, while no significant difference in this variable was observed over time in the CGs condition $(+6.6 \pm 5.2 \%$; ES $=0.33 \pm 0.16$, $P=0.121)$. The increase in RMS $A_{r}$ was likely higher after CON than CGs conditions, with a "moderate" standardized difference between conditions (ES $=-0.86 \pm 0.71)$. No significant differences in RMS $A_{r}$ were found for the gastrocnemius medialis within-and-between exercises $(P=0.246)$.

\section{Running Economy, Cardiorespiratory Parameters, and Stride Frequency}

The most significant changes in $\mathrm{VO}_{2}, V_{E}, \mathrm{HR}, \mathrm{RER}$, and $f$ were observed at the end of DHR in both CON and CGs conditions (Figure 4) while no significant differences in these variables were found in Post-1D, as compared to the beginning of each DHR (Table 3). At the end of DHR, a significant increase was observed in both conditions (i.e., time effect) for $\mathrm{VO}_{2}(\mathrm{CON}:+5.3 \pm 6.0 \%$; $\mathrm{ES}=0.51 \pm 0.31, P=0.049$ and CGs: $+6.8 \pm 5.6 \%$; $\mathrm{ES}=0.91 \pm 0.41 ; P=0.012), V_{E}$ $(\mathrm{CON}:+11.0 \pm 11.3 \% ; \mathrm{ES}=0.53 \pm 0.27, P=0.013$ and CGs: $+10.3 \pm 9.6 \% ; \mathrm{ES}=0.71 \pm 0.36 ; P=0.013)$, and HR $(\mathrm{CON}:+9.3 \pm 5.5 \% ; \mathrm{ES}=1.04 \pm 0.35 ; P=0.002$ and CGs: $+12.6 \pm 7.4 \%$; $\mathrm{ES}=1.26 \pm 0.39 ; P<0.001)$. In addition, RER values were significantly lower over time only for CGs ($4.9 \pm 4.4 \%$; ES $=-0.63 \pm 0.31 ; P=0.004)$, whereas no significant change in this variable was observed for $\operatorname{CON}(-3.1 \pm 2.2 \%$; $\mathrm{ES}=-0.40 \pm 0.15 ; P=0.066)$. Similarly, $f$ values were significantly lower over time only for CGs $(-2.2 \pm 2.1 \%$; ES $=-0.69 \pm 0.32$; $P=0.003)$, whereas no significant change in this variable was observed for $\mathrm{CON}(-1.3 \pm 2.7 \%$; $\mathrm{ES}=-0.37 \pm 0.39$; $P=0.119)$.

\section{Perceived Muscle Soreness and Jump Performance}

The magnitude of changes in perceived muscle soreness reported after CON and CGs conditions and in Post-1D is presented in Figure 5. A significant time $\times$ condition interaction was identified for scores in perceived muscle soreness only at quadriceps level $(P=0.026)$ which were significantly lower in Post-1D following CGs compared to CON, whereas no significant time $(P=0.069)$ or time $\times$ condition interaction effects $(P=0.117)$ were found at calves level. In addition, a significant decrease in countermovement jump was observed for $\mathrm{CON}(-6.7 \pm 7.1 \%$; $\mathrm{ES}=-0.57 \pm 0.32 ; P=0.003)$ and a strong trend for a decrease was identified for CGs ($4.2 \pm 8.4 \%$; ES $=-0.31 \pm 0.26 ; P=0.073$ ) following DHR. The significant alterations in jump performance were also identified in Post-1D for CON $(-7.7 \pm 5.8 \%$; ES $=-0.68 \pm 0.26$; $P=0.003)$ and CGs $(-5.1 \pm 7.5 \%$; ES $=-0.39 \pm 0.24$; $P=0.039)$ conditions. The mean values in countermovement jump were $36.2 \pm 4.0$ and $35.2 \pm 4.9 \mathrm{~cm}$ in Pre-DHR, $33.2 \pm 3.4$ and $33.6 \pm 4.3 \mathrm{~cm}$ in Post-DHR, $33.3 \pm 3.0$ and $33.2 \pm 3.3 \mathrm{~cm}$ in Post-1D for CON and CGs conditions, respectively. 


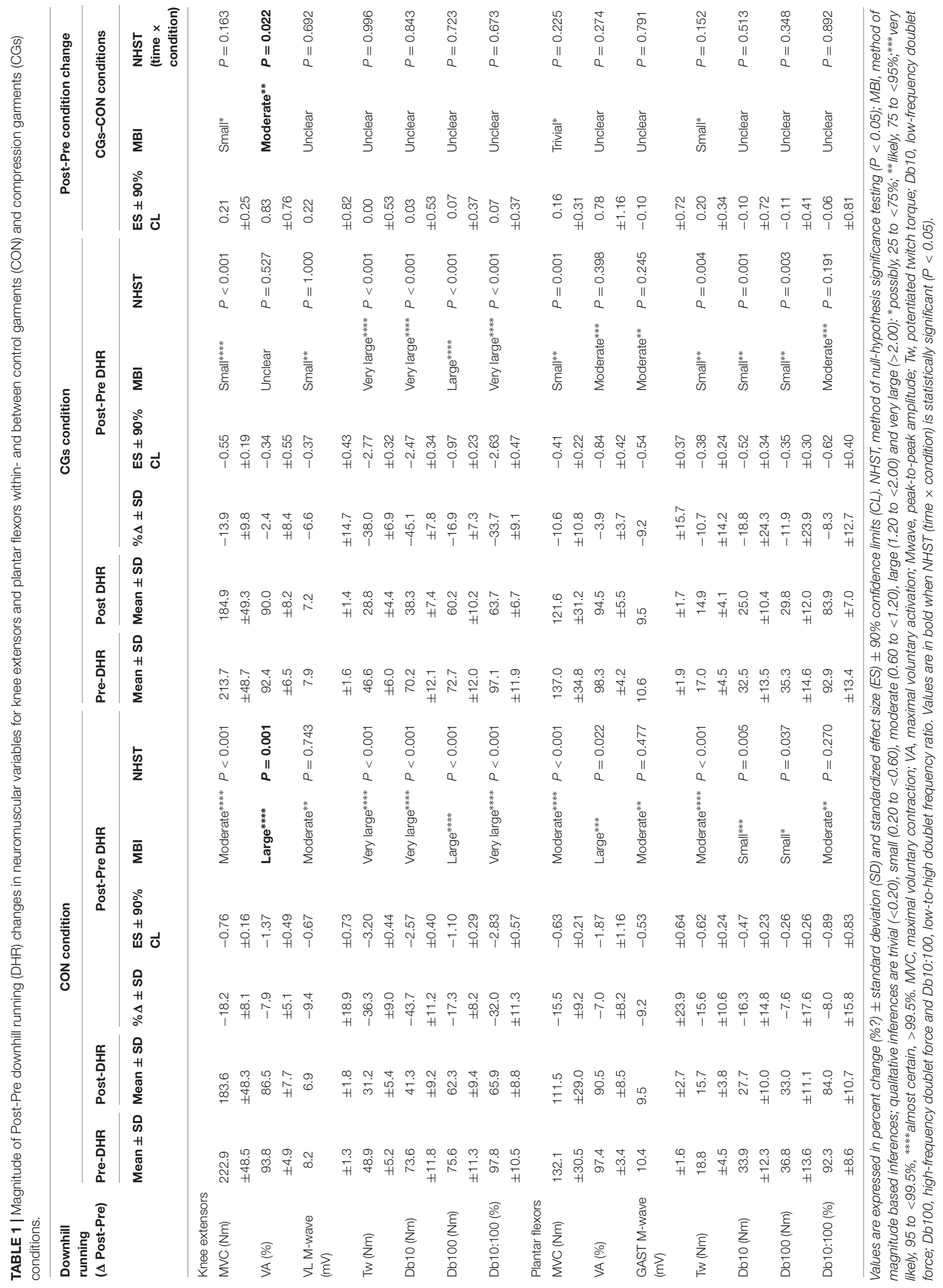




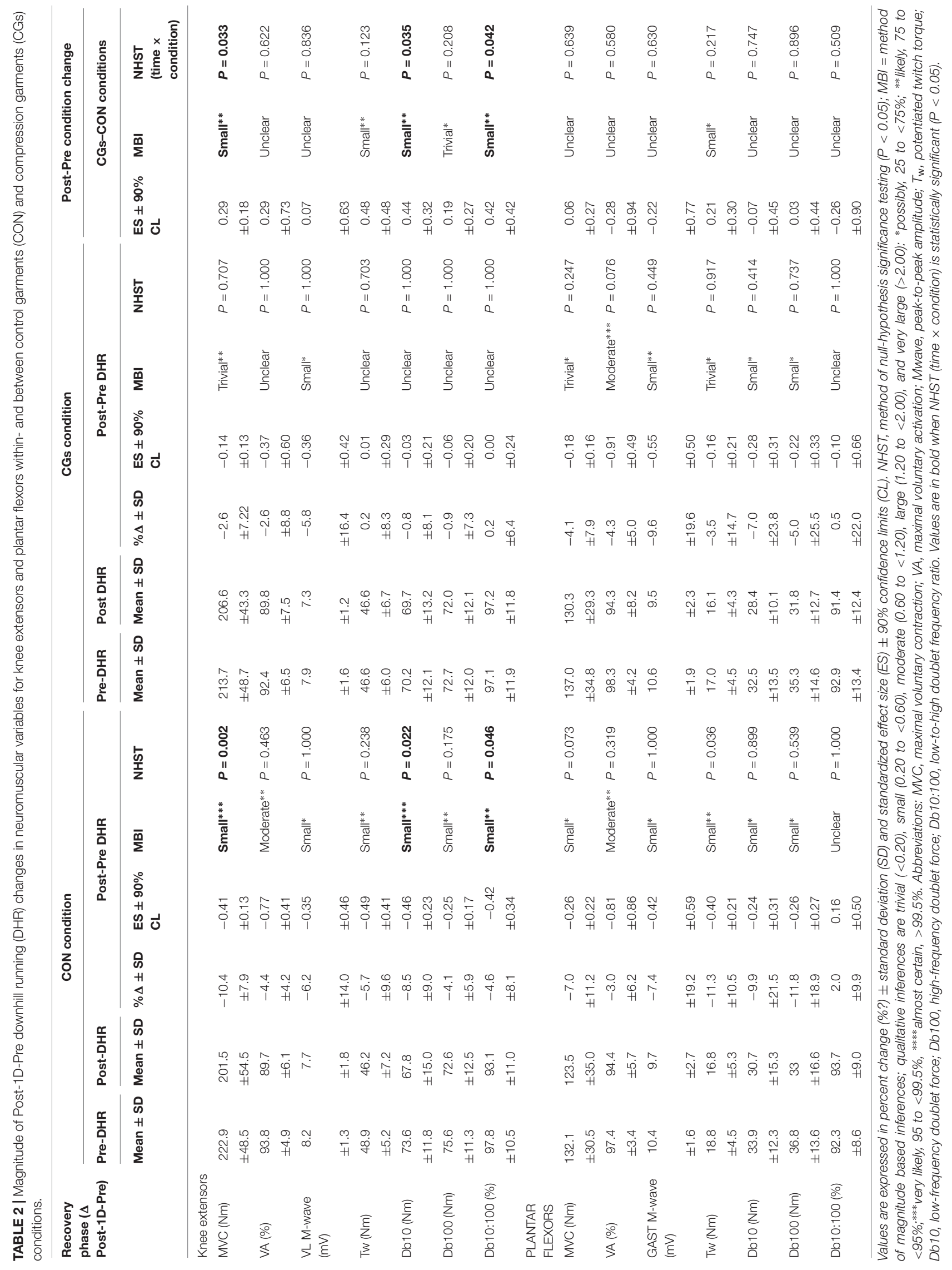




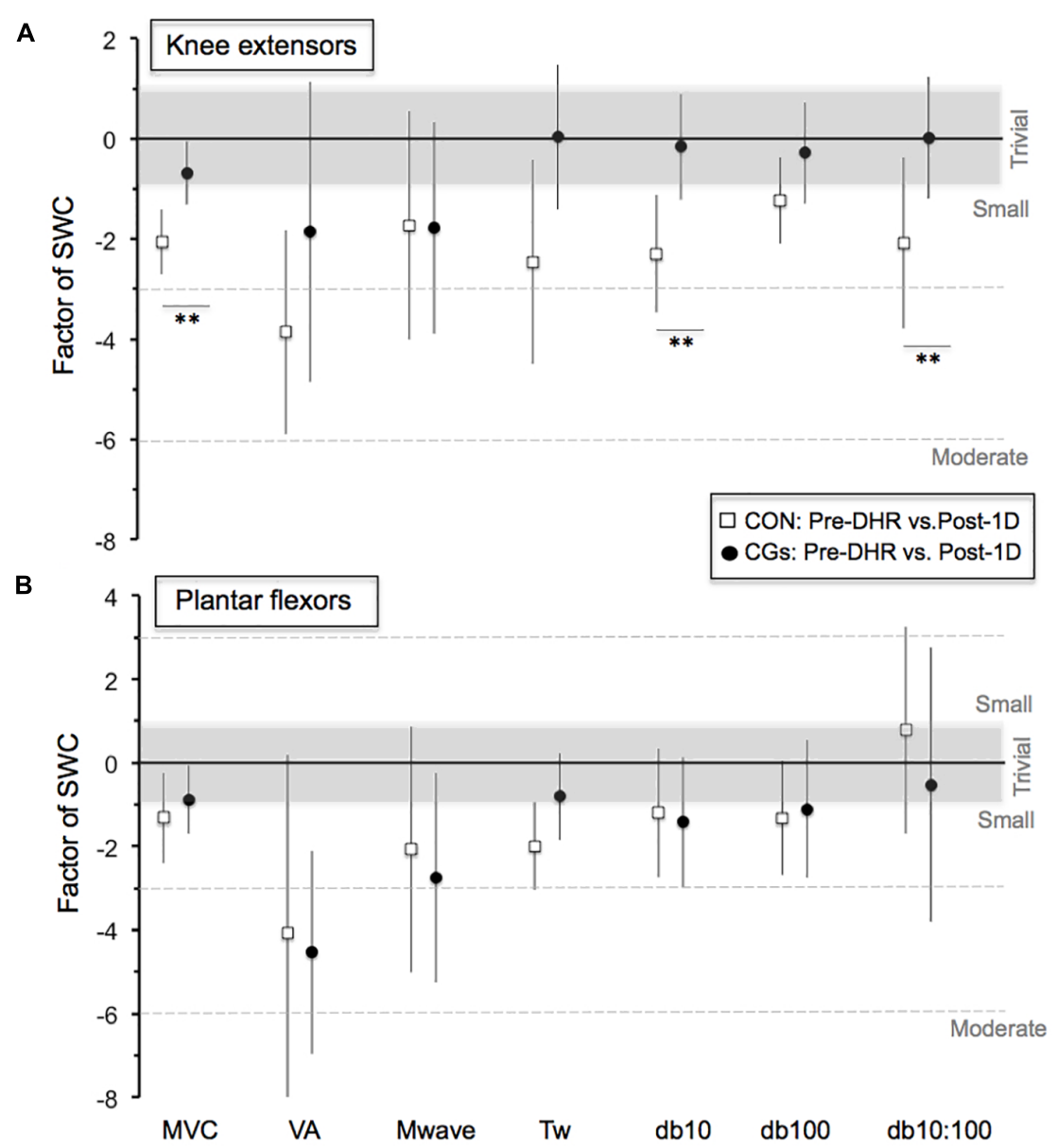

FIGURE 2 | Magnitude of changes in the neuromuscular responses (Pre-DHR/Post-1D) for knee extensors (A) and plantar flexors (B) for control (CON) and compression garments (CGs) exercises. The standardized differences are expressed as a factor of the smallest worthwhile change [SWC = ES (Cohen's $d$ ) of 0.2]. Bars indicate the $90 \%$ CLs. The number of asterisk $\left(^{*}\right)$ indicates the likelihood for the between-exercise differences to be substantial, with * indicating a possible and ** a likely difference. In the CGs exercise, the magnitude of changes in MVC, Db10, and Db10:100 for knee extensors was 1.5, 2.2, and 2.1 times greater than the SWC, respectively. Abbreviations: MVC, maximal voluntary contraction; VA, maximal voluntary activation; Mwave, peak-to-peak amplitude; Tw, potentiated twitch torque; Db10, low-frequency doublet force; Db100, high-frequency doublet force and Db10:100, low-to-high doublet frequency ratio.

\section{DISCUSSION}

We hypothesized that wearing high-pressure CGs during an intense downhill run would attenuate soft-tissue vibrations, acute and delayed alterations in muscle function and improve RE. Our hypotheses have been partially confirmed, as the most important findings of this study are (i) an attenuation of softtissue vibrations during DHR (only for the vastus lateralis) and a reduced VA deficit (only for KE) in the CGs condition, (ii) a deterioration in RE for both CGs and CON conditions, and (iii) a faster recovery of MVC and peripheral parameters at $24 \mathrm{~h}$ post-CGs with lesser muscle soreness (only for KE).

\section{Acute Effects of Wearing Compression Garments}

A reduction in $\mathrm{MVC}$ is a well-acknowledged and reliable index for assessing muscle damage within a whole muscle group (Damas, 2016). The magnitude of MVC decline appears to be directly related to the number of muscle fibers with myofibrillar disruption and/or excitation-contraction coupling failure (Raastad et al., 2010; Peake et al., 2017). Small to moderate decreases in MVC were observed immediately after DHR either in CGs or CON condition for KE $(-13.9 \pm 9.8$ and $-18.2 \pm 8.1 \%$, respectively) and $\mathrm{PF}$ muscles $(-10.6 \pm 10.8$ and $-15.5 \pm 9.2 \%$, respectively, Table 1). The significant decrements in MVC, whatever the condition, were lower than those measured in previous downhill studies using a 30-min treadmill exercise ( $\sim-20 \%$ for KE) (Chen et al., 2007) or a $6.5 \mathrm{~km}$ downhill trail run $(-18.6 \%$ for $\mathrm{KE}$ and $-25.4 \%$ for $\mathrm{PF}$ ) (Giandolini et al., 2016a). The observed discrepancies between studies are likely due to the differences in DHR training status of the subjects. Indeed, the subjects recruited in the present study had a high trail running background and/or practice and hence, all were highly accustomed to DHR before the starting of laboratory sessions. Overall, the acute MVC responses to the high DHR intensity $\left(\sim 4.2 \mathrm{~m} . \mathrm{s}^{-1}\right)$ might be specific to the training status of our 

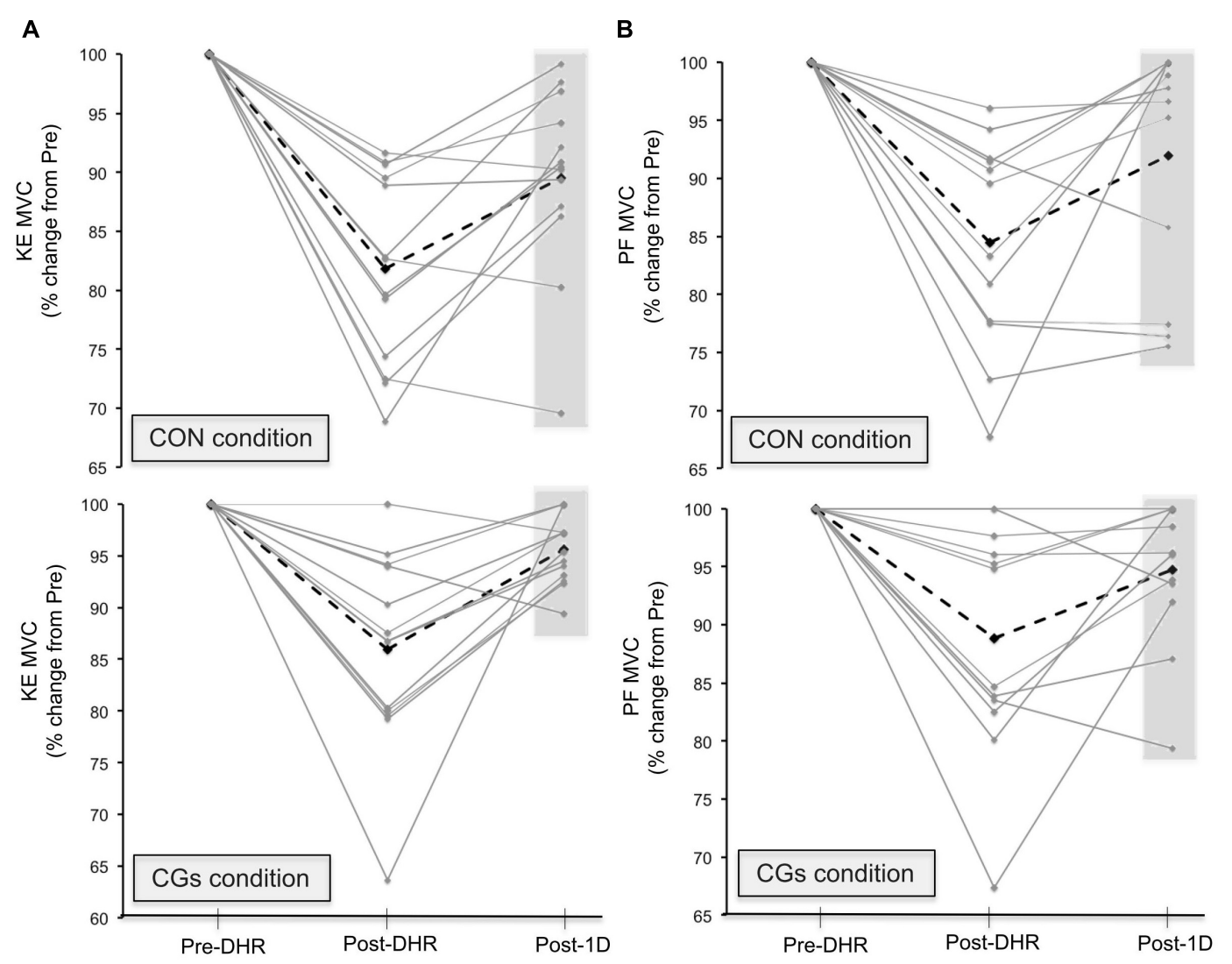

FIGURE 3 | Individual responses in maximal voluntary contraction (MVC) torques for knee extensors [KE (A)] and plantar flexors [PF (B)] muscles in Pre-downhill running (DHR), immediate Post-DHR, and following 1 day recovery (Post-1D). Values are expressed in percentage change from Pre-DHR. The black dotted line indicates the average MVC value for a given condition. The gray area indicates subjects that may be "responders" or "non-responders" to CGs exercises in Post-1D sessions. A great percentage of positive responders to KE MVC recovery was identified in the CGs exercise. Abbreviations: CON, control garments; CGs: compression garments.

population and thus provide valuable insights on the evaluation of muscle function following DHR in trained subjects.

Maximal voluntary contractions loss for $\mathrm{KE}$ and $\mathrm{PF}$ following DHR is usually related to alterations in both central and peripheral factors (Giandolini et al., 2016b). The current findings indicate small to large alterations in VA and peripheral variables (M-wave or Db10:100) for KE and PF, independently of the experimental condition, with greater changes in the peripheral components (Table 1). These data are consistent with those reported in previous laboratory and ecological downhill studies (Martin et al., 2004; Giandolini et al., 2016a). Thus, eccentric exercise such as DHR is known to induce severe lower limb tissue damage and low-frequency fatigue (i.e., decreased Db10:100), particularly for KE. Larger decreases in Db10:100 for $\mathrm{KE}$ (from -32.0 to $-33.7 \%$ ) compared to PF (from 8.0 to $-8.3 \%$ ) were observed in the present study, which are in line with those recently observed following a $6.5-\mathrm{km}$ downhill trail run (Giandolini et al., 2016a). Several mechanisms are proposed to characterize peripheral fatigue, including impairments in sarcolemmal action potential conduction and excitability (Piitulainen et al., 2008, 2010), depressed $\mathrm{Ca}^{2+}$ release from the sarcoplasmic reticulum (Hill et al., 2001; Martin et al., 2005) but also decreased in $\mathrm{Ca}^{2+}$ sensitivity and/or force produced by active cross-bridges (Place et al., 2010). Although using CGs has been shown to reduce muscle activation during prolonged level running, which might improve muscle function (Hsu et al., 2017), results of the present work do not support a beneficial effect of CGs on peripheral fatigue for KE and PF. The delay time for measuring muscle function (7-10 min after exercise termination) constitutes a methodological limitation, which may have counteracted the potential benefits of CGs on the extent of peripheral fatigue. In this regard, Froyd et al. (2013) demonstrated a rapid recovery of peripheral variables within the first $8 \mathrm{~min}$ of the recovery period, thus underestimating not only the extent of peripheral fatigue in our study (and previous reports) but also the potential beneficial effect of CGs.

Surprisingly, the most noticeable acute effect of wearing CGs was observed on the VA deficit. Indeed, the KE VA deficit was significantly lower following the CGs condition, compared to the CON condition ( -2.4 vs. $-7.9 \%$, respectively, Table 1). It is well documented that central drive is controlled by a combination of factors including excitatory and inhibitory reflex inputs from muscles, joints, tendons, and cutaneous afferents (Millet et al., 2012; Amann et al., 2015). Hence, an attenuated VA deficit, 

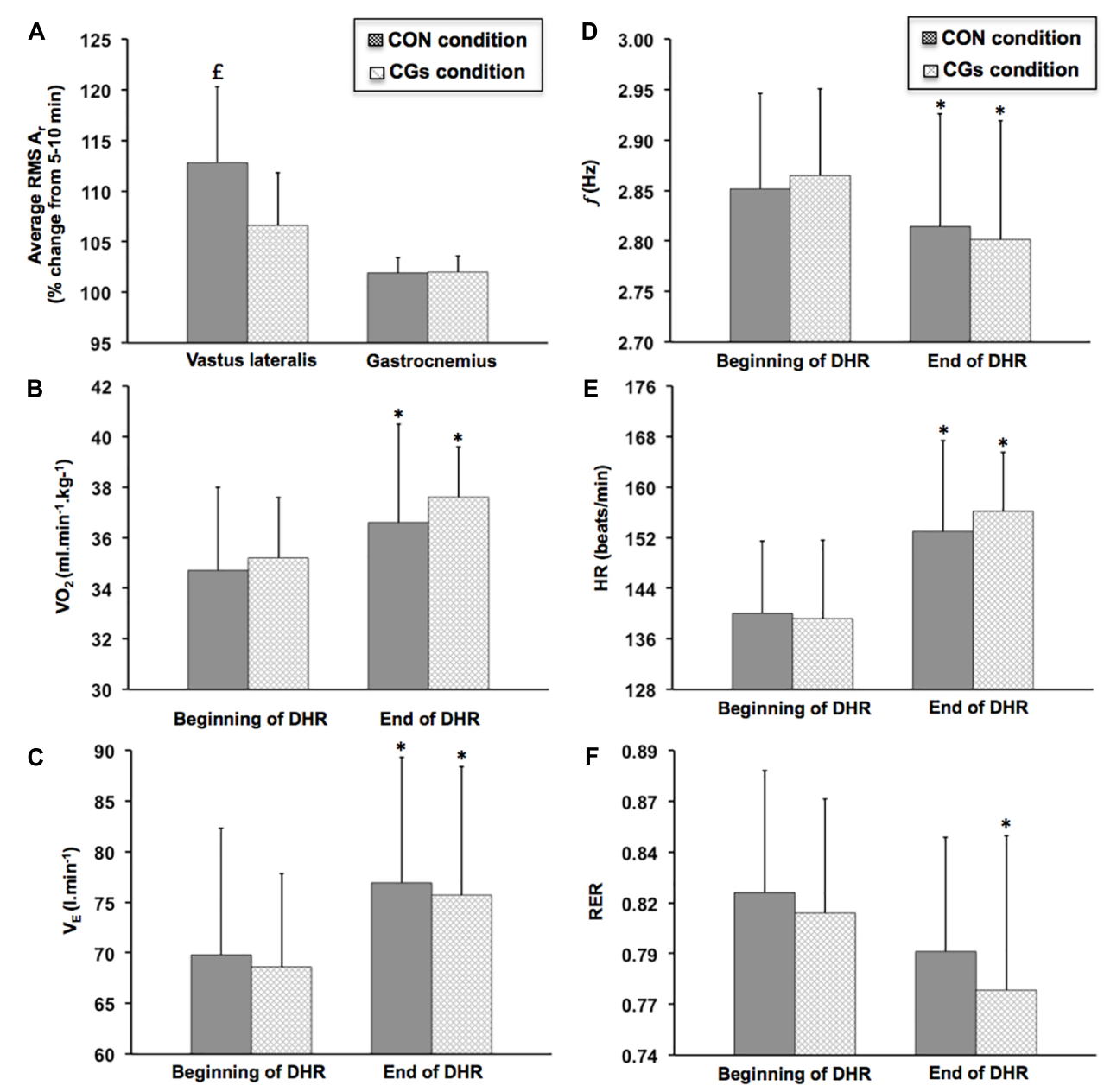

FIGURE 4 | Changes in average resultant acceleration for vastus lateralis and gastrocnemius medialis $\left[R M S A_{r}(\mathbf{A})\right]$, oxygen uptake $\left[V O_{2}(\boldsymbol{B})\right]$, ventilation $\left[V_{E}(\mathbf{C})\right]$, step frequency $[f(\mathbf{D})]$, heart rate $[\mathrm{HR}(\mathbf{E})]$, and respiratory exchange ratio $[R E R(\mathbf{F})]$ during the 40-min downhill runs performed with control garments $(\mathrm{CON})$ and compression garments (CGs). RMS $A_{r}$ was expressed as a function of time. $V_{2}, V_{E}, f$, HR, and RER were averaged from two time periods at the beginning (3-5

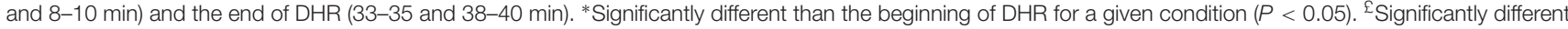
than the CGs condition $(P<0.05)$.

as reported following the CGs condition, could be attributed to a higher output from the motoneuron pool resulting not only from decreased inhibitory actions (group III/IV muscle afferents) but also through facilitation of Ia afferents inputs onto alpha motoneurons (Souron et al., 2017). In a recent literature review, Souron et al. (2017) reported that Ia afferents, which innervate muscle spindles, are the most responsive receptors to local vibratory stimuli, especially when muscles are stretched (as during DHR). Interestingly, a significant time effect on RMS $A_{r}$ values was identified, indicating an increase in RMS $A_{r}$ and thereby, soft-tissue vibrations over time for the vastus lateralis only in the CON condition (Figure 4A). Although no significant interaction effect was observed, the change in RMS $A_{r}$ was likely higher after CON than CGs conditions with a "moderate" standardized difference between conditions ( $\mathrm{ES}=-0.86 \pm 0.71$ ). Wearing CGs at the quadriceps level may have exerted dynamic immobilization reducing muscle oscillation and improving joint stability, and in turn, enhancing neural input (Kraemer et al., 2001; Doan et al., 2003). Although the analysis was limited to the vastus lateralis, the decrease in soft-tissue vibrations only in the CGs condition, that reflects an attenuation of impact forces (Friesenbichler et al., 2011), might contribute to the reduced VA deficit in the CGs condition. While vibrations were not local but naturally extended to overall quadriceps during DHR, we suggest that the decrease in soft-tissue vibrations for the vastus lateralis only in the CGs condition influences the feedback from muscle spindle afferents and reduces central drive alteration. Future mechanistic approach is necessary to better understand the mechanisms underlying the relationship between soft-tissue vibrations, muscle fatigue and CGs.

To date, laboratory studies quantifying soft-tissue vibrations were limited to level treadmill running during which no evaluation of muscle fatigue was carried out (Friesenbichler et al., 2011; Khassetarash et al., 2015). During level running, 


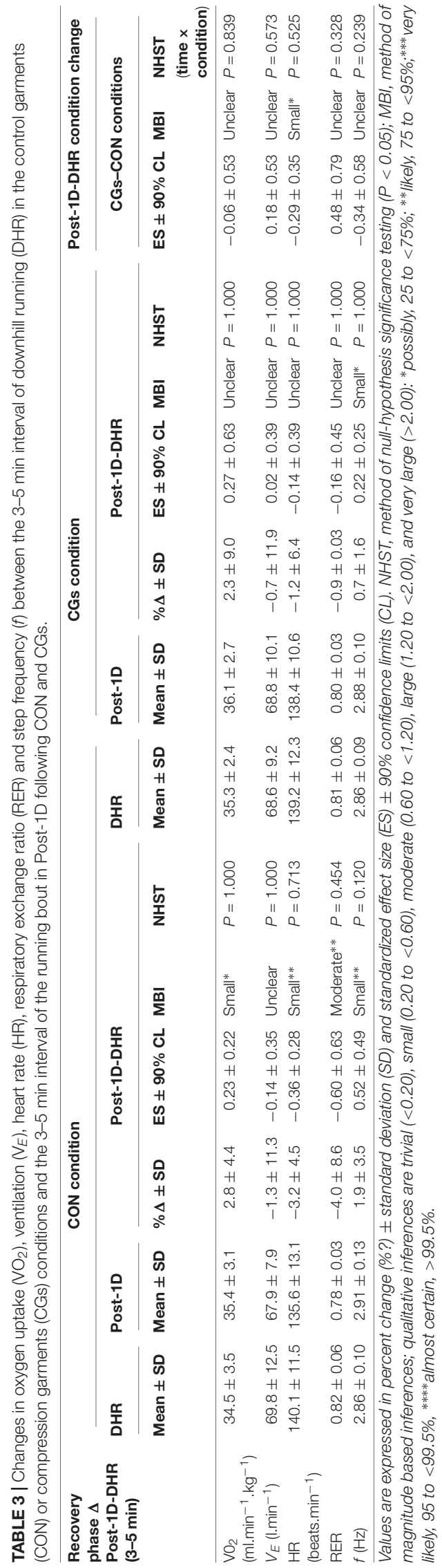

it has been suggested that muscles actively participate to the shock and vibration attenuation, according to the paradigm of "muscle tuning" proposed by (Nigg and Wakeling, 2001). In this paradigm, pre-activation and muscle activation intensities are adapted in accordance with the impact magnitude at ground contact in order to control soft-tissue vibrations (Wakeling et al., 2001; Boyer and Nigg, 2004). However, higher values in peak vertical impact and loading rate were observed during DHR exercises compared to uphill or level running exercises (Mizrahi et al., 2000; Gottschall and Kram, 2005), with an accentuated involvement of "muscle tuning" in such conditions. In the current study, we suggest that the protective mechanism of "muscle tuning" is accentuated in the CGs condition, especially on muscle mass substantially involved in shocks absorption (e.g., KE muscles). Indeed, a significant variation in soft-tissue vibrations (e.g., RMS $A_{r}$ ) was observed over time for the vastus lateralis only in the CON condition whereas no significant difference in RMS $A_{r}$ was found for the gastrocnemius medialis within-andbetween exercises (Figure 4A). It has been previously reported a greater eccentric work (in relation with higher volume and/or mass) for KE compared to PF muscles during DHR (Buczek and Cavanagh, 1990), which might be associated with higher shock absorption, thus locally affecting the magnitude of soft-tissue vibrations. Interestingly, when focused on the vastus lateralis, the difference between DHR conditions was likely beneficial in favor of CGs, as shown by the lower increase in RMS $A_{r}$ over time $(-5 \%)$ and the large ES $(-0.86 \pm 0.71)$ for this condition. Considering these results, wearing CGs during DHR might constitute a mechanical strategy to accentuate the muscle damping of soft-tissue vibrations especially for KE.

However, the beneficial effects of CGs on soft-tissue vibrations or VA were not associated with improved perceived muscle soreness scores and countermovement jump responses following DHR. Muscular power and strength as well as muscle soreness are the most common markers used to assess EIMD following eccentric exercises (Hill et al., 2014). It has been demonstrated that muscle soreness, reflecting connective tissue damage and inflammation in the extracellular matrix (Peake et al., 2017), appears to be independent of other markers such as MVC (Nosaka et al., 2002). In the present study, the lack of differences in perceived muscle soreness scores between sessions immediately after DHR might be explained by the high DHR intensity sustained for both conditions (thus affecting immediately perceived muscle soreness responses) and/or the short delay for measuring perceived muscle soreness after DHR $(\sim 2 \mathrm{~min})$. Indeed, perceived muscle soreness are known to increase in the hours following eccentric exercises and peak after 1-3 days (Cheung et al., 2003). Otherwise, although significant decreased (or strong tendency) countermovement jump height were found after DHR, no difference in jump performance was identified between sessions, confirming previous results obtained after simulated trail running races (Vercruyssen et al., 2014; Kerhervé et al., 2017). Considering these elements, MVC appears to be the most sensitive marker to assess acute effects of DHR on muscle damage (Damas, 2016).

Finally, altered RE, $V_{E}$, RER, and HR responses were observed over time and regardless of conditions (Figure 4), suggesting 
a relationship between these cardiorespiratory parameters. As previously reported by Chen et al. (2007), it is likely that the changes in $\mathrm{HR}, V_{E}$, and RER are indicative of an altered RE (i.e., significant increase in the $\mathrm{VO}_{2}$ response) among $\mathrm{DHR}$ sessions. For instance, HR values were significantly higher over time (from +9.3 to $+12.6 \%$, Figure $4 \mathrm{E}$ ) that might be related to the $\mathrm{VO}_{2}$ drift but also, to the potential increase of core body temperature experienced during DHR (Westerlind et al., 1992). Time course of RE responses during DHR are relatively scarce in literature (Dick and Cavanagh, 1987; Westerlind et al., 1992; Gavin et al., 2015), with no reports in trained runners accustomed to eccentric work. In the current investigation, we reported a 5.3$6.8 \%$ increase in RE (Figure $4 \mathrm{~B}$ ) at the end of DHR for both conditions. These RE alterations are lower than those reported in previous studies (Dick and Cavanagh, 1987; Westerlind et al., 1992) indicating substantial increases in RE (expressed as $\mathrm{VO}_{2}$ ) over time $(>+10 \%)$, probably due to the low training status of the subjects. Moreover, stride pattern can affect RE during fatiguing and non-fatiguing running (Moore, 2016). For instance, we reported a significant decrease in $f$ (Figure 4D) in the CGs condition that might be related to the significant increase in RE in this condition. These findings are in agreement with previous work showing a similar RE-stride pattern relationship in trained subjects running for $1 \mathrm{~h}$ at the fastest possible speed (Hunter and Smith, 2007). This suggests that subjects of the present work modify their RE responses while adjusting an optimal stride pattern with fatigue. In addition, several hypotheses may be proposed to explain the altered RE over time for both DHR exercises, including an increased motor unit recruitment to maintain prolonged DHR exercises and/or preferential type II fiber recruitment (Dick and Cavanagh, 1987; Douglas et al., 2017) but also, substantial normal impact force and parallel braking force peaks (Gottschall and Kram, 2005). Therefore, RE responses in the present study are consistent with recent investigations reporting changes in $\mathrm{RE}$ responses independently of wearing CGs either during level running of short duration or prolonged trail running in well-trained populations (Stickford et al., 2015; Vercruyssen et al., 2017). Based on a recent study focusing on the relationship between downhill training and chronic RE responses (Shaw et al., 2018), RE does not appear to be the most sensitive index to evaluate the efficacy of an intervention in already welltrained subjects.

\section{Delayed Effects of Wearing Compression Garments}

This study is the first to demonstrate that the completion of a DHR exercise while wearing CGs may exert meaningful differences between acute and delayed neuromuscular responses. In contrast with acute effects of CGs described above, peripheral alterations were strongly reduced for KE compared to PF muscles at $24 \mathrm{~h}$ post-CGs (Table 2), suggesting that the use of CGs during strenuous DHR may constitute a strategy for runners to enhance subsequent recovery of KE muscles. All subjects wore CGs only during DHR, thus excluding the potential recovering effect of wearing CGs in the hours following eccentric exercises (Hill et al., 2014). Reductions in KE MVC were $-2.6 \%$ at $24 \mathrm{~h}$
post-CGs (vs. $-10.4 \%$ at $24 \mathrm{~h}$ post-CON), and were substantially lower that those reported at 24-h following 30-45 min DHR exercises $(-17.0 \%)$ in physically active subjects (Malm et al., 2004; Maeo et al., 2017) or after a $6.5 \mathrm{~km}$ downhill trail run session ( $-8.5 \%$ at post $-48 \mathrm{~h}$ ) in trained runners (Giandolini et al., 2016a). These discrepancies in MVC responses between studies at $24 \mathrm{~h}$ post-DHR may be mainly explained by differences in training status. All participants in the present work had a high DHR training status and thus, a better recovery capacity for this exercise modality (Douglas et al., 2017; Hyldahl et al., 2017). For instance, the percentage of positive responders to MVC recovery was particularly elevated for KE (Figure 3) and might represent a specificity of our population.

This delayed effect of CGs on the reduction in MVC loss is consistent with those previously reported (Bieuzen et al., 2014), indicating likely and possibly beneficial effects of CGs on MVC losses at 1 and $24 \mathrm{~h}$ post-trail running, respectively. These authors have related the delayed benefits of CGs to the reduction in muscle oscillation and/or mechanical stress induced during trail running. In support of this hypothesis, the reduction in soft-tissue vibrations observed only in the CGs condition for the vastus lateralis may have contributed to the improvement of muscle recovery, notably by reducing peripheral alterations. Interestingly, a rapid recovery in $\mathrm{Db} 10$ and $\mathrm{Db} 10: 100$ variables for KE was also observed at $24 \mathrm{~h}$ post-CGs (Table 2), suggesting a reduced failure in excitation-contraction coupling mechanisms. Such restoration of these neuromuscular variables was not observed at $24 \mathrm{~h}$ post-CGs for PF, excepted for $T_{w}$ values. From a mechanistic perspective, future research is warranted to evaluate, within the recovery phase, the vibration damping properties which may vary with fatigue (Friesenbichler et al., 2011; Khassetarash et al., 2015) and its relationship with EIMD.

Previous theories have been proposed to describe the extent of EIMD, including sarcomeres disruption (e.g., the "popping sarcomere" hypothesis") or damage to the excitation-contraction coupling system (Morgan and Proske, 2004; Proske and Morgan, 2001). In a recent review, Douglas et al. (2017) have reported that overstretched sarcomeres induce ultrastructural myofibrillar disruption, overloading sarcolemma and t-tubules structures and in turn, excitation-contraction coupling dysfunction. In addition, extensive EIMD may lead to inflammatory syndrome, triggering nociceptor stimulation (group III and IV afferents) and subsequently, muscle soreness (Proske and Morgan, 2001; Peake et al., 2017). Considering these statements, we assume that wearing CGs during an intense and prolonged DHR may have "mechanically" preserved KE muscles, which are strongly exposed to muscle damage and peripheral fatigue during DHR (Giandolini et al., 2016b; Maeo et al., 2017). This "protective effect" exerted by the use of high-pressure CGs might be effective especially in the hours following exercise where EIMD symptoms begin to spread intensively within skeletal muscles (Peake et al., 2017). This hypothesis is consistent with perceived muscle soreness scores reported for quadriceps (Figure 5), that were significantly lower at $24 \mathrm{~h}$ post-CGs, whereas no significant changes in perceived muscle soreness were found between conditions after DHR. While countermovement jump performances did not change within the recovery phase, 


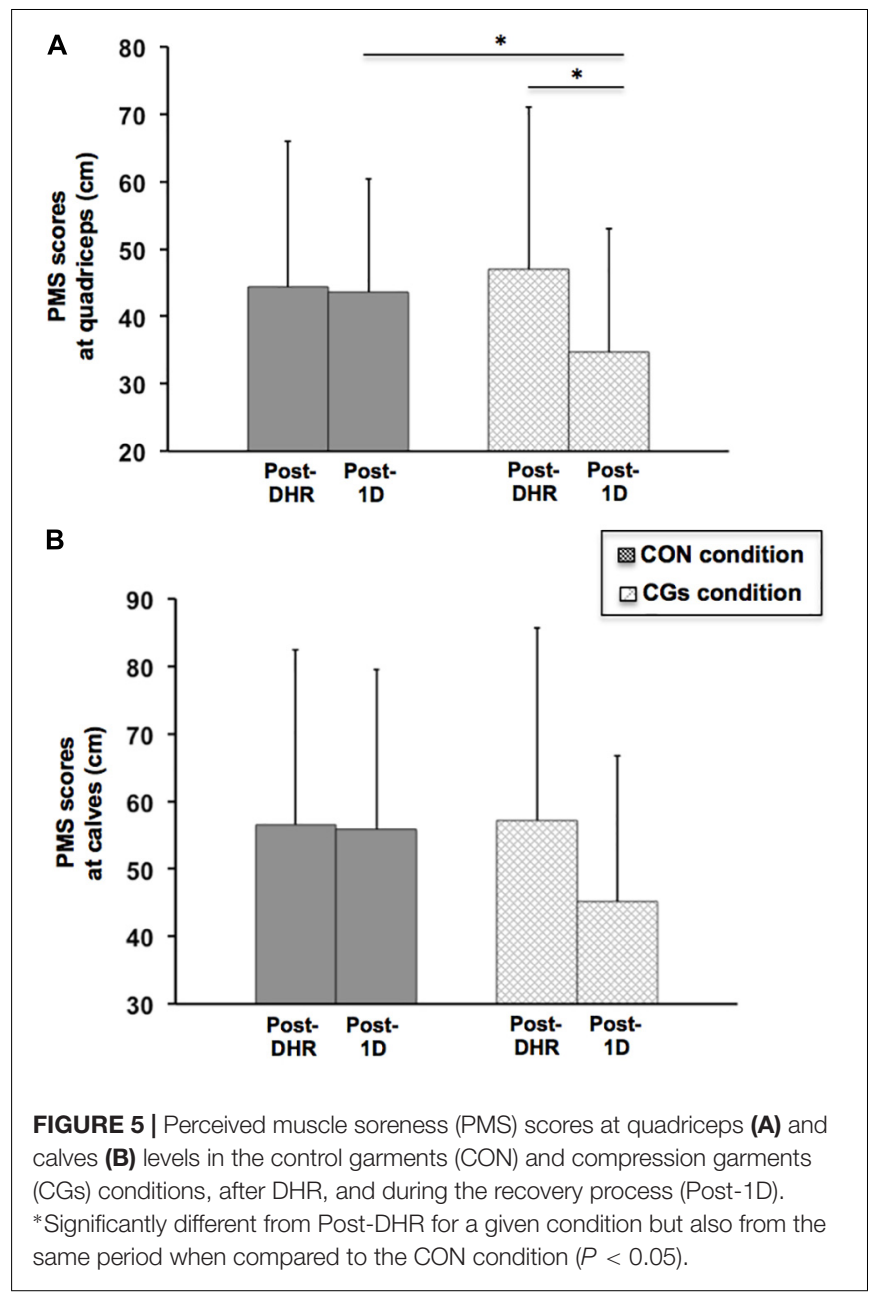

perceived muscle soreness index seems to be more sensitive in the hours following DHR and might be related to lesser peripheral alterations. Based on reviews considering CGs as a strategy for enhancing recovery from muscle damage and inflammation (Brown et al., 2017; Peake et al., 2017; Dupuy et al., 2018), we suggest that wearing high-pressure CGs (especially for KE) during DHR contribute to the enhanced muscle recovery process by exerting an exercise-induced "mechanical protective effect". Further research is warranted to know whether this "protective effect" may be potentiated by the use of CGs during the recovery phase, notably on KE muscles.

The reduction of EIMD and peripheral fatigue at $24 \mathrm{~h}$ post-CGs was not associated with responses in $\mathrm{RE}$ and cardiorespiratory parameters (Table 3) that were unchanged, whatever the condition. These findings are consistent with $\mathrm{RE}$ responses reported $24 \mathrm{~h}$ after the completion of a 30 min DHR exercise in physically active males (Mizuno et al., 2016). However, in this investigation, CGs were not used during DHR (only during the $24 \mathrm{~h}$ recovery period), making the comparison with our data difficult. Regardless of the use of CGs, it has been reported that DHR induced an alteration in $\mathrm{RE}$ at $48 \mathrm{~h}$ post-exercise in well-trained runners and triathletes (Braun and Dutto, 2003), which lasted for 3 days in soccer players (Chen et al., 2007) and 5 days in untrained subjects (Chen et al., 2009). In these studies, altered RE responses were associated with increases in EIMD markers (e.g., MVC, creatine kinase activity) or changes in stride mechanics (e.g., increased stride frequency), highlighting a relationship between RE and muscle damage in populations unaccustomed to DHR exercises. Although our experimental design was quite different than those used in these previous investigations, the present work indicates no significant differences in RE and cardiorespiratory responses in Post-1D among conditions, as compared to the first 5-min of DHR, and shows that during the recovery phase, these variables returned rapidly to values obtained at the beginning of DHR in highly trained runners. On the opposite, $f$ values were significantly higher in Post-1D, as reported in previous work (Chen et al., 2007). Considering acute and delayed RE responses, we postulate that RE is a too "robust" indicator to be sensitive to certain external strategies, such as wearing CGs, in already well-trained subjects (Shaw et al., 2018).

Some methodological limitations must be considered such as the delay time for measuring muscle fatigue (710 min after DHR), possibly counteracting not only the potential benefits of CGs on acute central and peripheral adaptations (Froyd et al., 2013) but also the lack of mechanistic explanation of the "protective effect" observed in the CGs condition and its consequences on muscle damage and peripheral fatigue during the recovery phase. Within this framework, the temporal analysis of soft-tissue vibrations only during DHR and limited to the vastus lateralis as well as the lack of calculation of damping characteristics did not allow to infer on the potential relationship between vibrations and muscle function in the CGs condition and the recovery phase. It has been shown that soft tissue vibrations tend to increase as fatigue develops from a level running protocol (Friesenbichler et al., 2011). In this regard, a methodology based on the complex analysis of vibratory properties (Enders et al., 2012) might be useful to determine whether the musculoskeletal system is able to further dampen the increased vibration amplitude with the use of CGs, and how vibratory properties may act, in turn, on muscle damage and peripheral fatigue during and after exercise. Additionally, it would be interesting in future investigations to use histological analyses of muscle biopsies (Valle et al., 2013) or transverse relaxation time-weighted magnetic resonance imaging (Maeo et al., 2017) to better understand the impact of wearing CGs on the extent of muscle damage (e.g., sarcomeres disruption) and inflammatory edema following DHR. Finally, although a great majority of beneficial effects was reported on $\mathrm{KE}$ in the hours following DHR, it remains however uncertain whether such benefits are primarily linked to the use of thigh compression during DHR or if the "protective effect" results in the combined effects of calves and quadriceps compression. Using different apparel strategies, further work could isolate the responses of each muscular compartment compressed on muscle damage and/or muscle fatigue during running and within the recovery phase. 


\section{CONCLUSION AND PERSPECTIVES}

This study shows that the use of high-pressure CGs during DHR induces beneficial effects on soft-tissue vibrations, acute and delayed neuromuscular responses, and muscle soreness, in well-trained off-road runners. The attenuation of soft-tissue vibrations only in the CGs condition might contribute, at least in part, to the reduced VA deficit immediately after DHR and, to the improved muscle function during the recovery phase. This study suggests that the use of CGs exerts an exercise-induced "mechanical protective effect," that might constitute an external strategy for runners, especially to tolerate a high training load or to optimize recovery process within multi-stage races. Given that our findings were observed in highly trained trail runners, we assume that the observed effects with the use of CGs would be even greater in less trained or recreational subjects. Future studies are required to better understand the extent to which wearing CGs may alter the degree of muscle damage or reduce decrements in central and peripheral fatigue-related variables for KE muscles. Moreover, a detailed analysis of the contribution of wearing CGs during DHR to inflammatory mechanisms would be interesting, since they are involved in cellular signaling allowing adaptation to muscle regeneration following training

\section{REFERENCES}

Amann, M., Sidhu, S. K., Weavil, J. C., Mangum, T. S., and Venturelli, M. (2015). Autonomic responses to exercise: group III/IV muscle afferents and fatigue. Auton. Neurosci. 188, 19-23. doi: 10.1016/j.autneu.2014.10.018

Balsalobre-Fernández, C., Agopyan, H., and Morin, J.-B. (2016). The validity and reliability of an iphone app for measuring running mechanics. J. Appl. Biomech. 33, 222-226. doi: 10.1123/jab.2016-2104

Balsalobre-fernández, C., Glaister, M., and Lockey, R. A. (2015). The validity and reliability of an iPhone app for measuring vertical jump performance. J. Sports Sci. 33, 1574-1579. doi: 10.1080/02640414.2014.996184

Beliard, S., Chauveau, M., Moscatiello, T., Cros, F., Ecarnot, F., and Becker, F. (2014). Compression garments and exercise: no influence of pressure applied. J. Sports Sci. Med. 14, 75-83.

Bieuzen, F., Brisswalter, J., Easthope, C., Vercruyssen, F., Bernard, T., and Hausswirth, C. (2014). Effect of wearing compression stockings on recovery after mild exercise-induced muscle damage. Int. J. Sports Physiol. Perform. 9, 256-264. doi: 10.1123/IJSPP.2013-0126

Boyer, K. A., and Nigg, B. M. (2004). Muscle activity in the leg is tuned in response to impact force characteristics. J. Biomech. 37, 1583-1588. doi: 10. 1016/J.JBIOMECH.2004.01.002

Braun, W. A., and Dutto, D. J. (2003). The effects of a single bout of downhill running and ensuing delayed onset of muscle soreness on running economy performed 48 h later. Eur. J. Appl. Physiol. 90, 29-34. doi: 10.1007/s00421-0030857-8

Brown, F., Gissane, C., Howatson, G., van Someren, K., Pedlar, C., and Hill, J. (2017). Compression garments and recovery from exercise: a meta-analysis. Sports Med. 47, 2245-2267. doi: 10.1007/s40279-017-0728-9

Buchheit, M. (2016). The numbers will love you back in return - i promise. Int. J. Sports Physiol. Perform. 11, 551-554. doi: 10.1123/IJSPP.2016-0214

Buczek, F. L., and Cavanagh, P. R. (1990). Stance phase knee and ankle kinematics and kinetics during level and downhill running. Med. Sci. Sports Exerc. 22, 669-677. doi: 10.1249/00005768-199010000-00019

Chen, T. C., Chen, H., Wu, C., Lin, M., Chen, C., Wang, L., et al. (2007). Changes in running economy following a repeated bout of downhill running. J. Exerc. Sci. Fit. 5, 109-117. doi: 10.1249/00005768-200605001-01640

Chen, T. C., Nosaka, K., Lin, M.-J., Chen, H.-L., and Wu, C.-J. (2009). Changes in running economy at different intensities following downhill running. J. Sports Sci. 27, 1137-1144. doi: 10.1080/02640410903062027
(Peake et al., 2017). It would thus be necessary to ensure that a usual wearing of CGs during training does not interfere with muscular adaptation, especially in recreational or moderately trained subjects.

\section{AUTHOR CONTRIBUTIONS}

All authors contributed to the study conception, analysis and interpretation, drafting the paper, and gave their final approval of the manuscript.

\section{FUNDING}

This research was supported using specific funds and equipment from compression garment manufacturer Salomon (France).

\section{ACKNOWLEDGMENTS}

The authors would like to thank all the participants for their effort and valuable time.

Cheung, K., Hume, P., and Maxwell, L. (2003). Delayed onset muscle soreness?: treatment strategies and performance factors. Sports Med. 33, 145-164. doi: 10.2165/00007256-200333020-00005

Coza, A., Nigg, B. M., and Fliri, L. (2010). Quantification of soft-tissue vibrations in running: accelerometry versus high-speed motion capture. J. Appl. Biomech. 26, 367-372. doi: 10.1123/jab.26.3.367

Damas, F. (2016). Susceptibility to exercise-induced muscle damage?: a cluster analysis with a large sample. Int. J. Sports Med. 37, 633-640. doi: 10.1055/s0042-100281

Dewolf, A. H., Peñailillo, L. E., and Willems, P. A. (2016). The rebound of the body during uphill and downhill running at different speeds. J. Exp. Biol. 219, 2276-2288. doi: 10.1242/jeb.142976

Dick, R. W., and Cavanagh, P. R. (1987). An explanation of the upward drift in oxygen uptake during prolonged sub-maximal downhill running. Med. Sci. Sports Exerc. 19, 310-317. doi: 10.1249/00005768-198706000-00019

Doan, B. K., Kwon, Y. H., Newton, R. U., Shim, J., Popper, E. M., Rogers, R. A., et al. (2003). Evaluation of a lower-body compression garment. J. Sports Sci. 21, 601-610. doi: 10.1080/0264041031000101971

Douglas, J., Pearson, S., Ross, A., and McGuigan, M. (2017). Eccentric exercise: physiological characteristics and acute responses. Sports Med. 47, 663-675. doi: 10.1007/s40279-016-0624-8

Dupuy, O., Douzi, W., Theurot, D., Bosquet, L., and Dugué, B. (2018). An evidence-based approach for choosing post-exercise recovery techniques to reduce markers of muscle damage, soreness, fatigue, and inflammation: a systematic review with meta-analysis. Front. Physiol. 9:403. doi: 10.3389/fphys. 2018.00403

Easthope, C. S., Hausswirth, C., Louis, J., Lepers, R., Vercruyssen, F., and Brisswalter, J. (2010). Effects of a trail running competition on muscular performance and efficiency in well-trained young and master athletes. Eur. J. Appl. Physiol. 110, 1107-1116. doi: 10.1007/s00421-010-1597-1

Enders, H., von Tscharner, V., and Nigg, B. M. (2012). Analysis of damped tissue vibrations in time-frequency space: a wavelet-based approach. J. Biomech. 45, 2855-2859. doi: 10.1016/j.jbiomech.2012.08.027

Eston, R. G., Mickleborough, J., and Baltzopoulos, V. (1995). Eccentric activation and muscle damage?: biomechanical and physiological considerations during downhill running. Br. J. Sports Med. 29, 89-94. doi: 10.1136/bjsm.29.2.89

Friesenbichler, B., Stirling, L. M., Federolf, P., and Nigg, B. M. (2011). Tissue vibration in prolonged running. J. Biomech. 44, 116-120. doi: 10.1016/j. jbiomech.2010.08.034 
Froyd, C., Millet, G. Y., and Noakes, T. D. (2013). The development of peripheral fatigue and short-term recovery during self-paced high-intensity exercise. J. Physiol. 591, 1339-1346. doi: 10.1113/jphysiol.2012.245316

Gavin, J. P., Myers, S. D., and Willems, M. E. T. (2015). The effect of glycogen reduction on cardiorespiratory and metabolic responses during downhill running. Eur. J. Appl. Physiol. 115, 1125-1133. doi: 10.1007/s00421-014-3094-4

Giandolini, M., Horvais, N., Rossi, J., Millet, G. Y., Morin, J. B., and Samozino, P. (2016a). Acute and delayed peripheral and central neuromuscular alterations induced by a short and intense downhill trail run. Scand. J. Med. Sci. Sports 26, 1321-1333. doi: 10.1111/sms.12583

Giandolini, M., Vernillo, G., Samozino, P., Horvais, N., Edwards, W. B., Morin, J. B., et al. (2016b). Fatigue associated with prolonged graded running. Eur. J. Appl. Physiol. 116, 1859-1873. doi: 10.1007/s00421-016-3437-4

Giandolini, M., Horvais, N., Rossi, J., Millet, G. Y., Morin, J. B., and Samozino, P. (2017). Effects of the foot strike pattern on muscle activity and neuromuscular fatigue in downhill trail running. Scand. J. Med. Sci. Sports 27, 809-819. doi: $10.1111 /$ sms.12692

Gottschall, J. S., and Kram, R. (2005). Ground reaction forces during downhill and uphill running. J. Biomech. 38, 445-452. doi: 10.1016/j.jbiomech.2004.04.023

Hill, C. A., Thompson, M. W., Ruell, P. A., Thom, J. M., and White, M. J. (2001). Sarcoplasmic reticulum function and muscle contractile character following fatiguing exercise in humans. J. Physiol. 531, 871-878. doi: 10.1111/J.1469-7793. 2001.0871H.X

Hill, J., Howatson, G., van Someren, K., Leeder, J., and Pedlar, C. (2014). Compression garments and recovery from exercise-induced muscle damage: a meta-analysis. Br. J. Sports Med. 48, 1340-1346. doi: 10.1136/bjsports-2013092456

Hopkins, W. G., Marshall, S. W., Batterham, A. M., and Hanin, J. (2009). Progressive statistics for studies in sports medicine and exercise science. Med. Sci. Sports Exerc. 41, 3-12. doi: 10.1249/MSS.0b013e318 $18 \mathrm{cb} 278$

Hsu, W.-C., Tseng, L.-W., Chen, F.-C., Wang, L.-C., Yang, W.-W., Lin, Y.-J., et al. (2017). Effects of compression garments on surface EMG and physiological responses during and after distance running. J. Sport Health Sci. 1-7. (in press). doi: $10.1016 /$ j.jshs.2017.01.001

Hunter, I., and Smith, G. A. (2007). Preferred and optimal stride frequency, stiffness and economy: changes with fatigue during a 1-h high-intensity run. Eur. J. Appl. Physiol. 100, 653-661. doi: 10.1007/s00421-007-0456-1

Hyldahl, R. D., Chen, T. C., and Nosaka, K. (2017). Mechanisms and mediators of the skeletal muscle repeated bout effect. Exerc. Sport Sci. Rev. 45, 24-33. doi: 10.1249/JES.0000000000000095

Jubeau, M., Rupp, T., Temesi, J., Perrey, S., Wuyam, B., Millet, G. Y., et al. (2017). Neuromuscular fatigue during prolonged exercise in hypoxia. Med. Sci. Sports Exerc. 49, 430-439. doi: 10.1249/MSS.0000000000001118

Kerhervé, H. A., Samozino, P., Descombe, F., Pinay, M., Millet, G. Y., Pasqualini, M., et al. (2017). Calf compression sleeves change biomechanics but not performance and physiological responses in trail running. Front. Physiol. 8:247. doi: 10.3389/fphys.2017.00247

Khassetarash, A., Hassannejad, R., Ettefagh, M. M., and Sari-Sarraf, V. (2015). Fatigue and soft tissue vibration during prolonged running. Hum. Mov. Sci. 44, 157-167. doi: 10.1016/j.humov.2015.08.024

Kraemer, W. J., Bush, J. A., Wickham, R. B., Denegar, C. R., Gómez, A. L., Gotshalk, L. A., et al. (2001). Influence of compression therapy on symptoms following soft tissue injury from maximal eccentric exercise. J. Orthop. Sports Phys. Ther. 31, 282-290. doi: 10.2519/jospt.2001.31.6.282

MacRae, B. A., Cotter J. D., and Laing, R. M. (2011). Compression garments and exercise: Garment considerations, physiology and performance. Sport Med. 41, 815-843. doi: 10.2165/11591420-000000000-00000

Maeo, S., Ando, Y., Kanehisa, H., and Kawakami, Y. (2017). Localization of damage in the human leg muscles induced by downhill running. Sci. Rep. 7:5769. doi: 10.1038/s41598-017-06129-8

Malm, C., Sjödin, B., Sjöberg, B., Lenkei, R., Renström, P., Lundberg, I. E., et al. (2004). Leukocytes, cytokines, growth factors and hormones in human skeletal muscle and blood after uphill or downhill running. J. Physiol. 556, 983-1000. doi: 10.1113/jphysiol.2003.056598

Martin, V., Millet, G. Y., Lattier, G., and Perrod, L. (2005). Why does knee extensor muscles torque decrease after eccentric-type exercise? J. Sports Med. Phys. 45, $143-151$.
Martin, V., Millet, G. Y., Martin, A., Deley, G., and Lattier, G. (2004). Assessment of low-frequency fatigue with two methods of electrical stimulation. J. Appl. Physiol. 97, 1923-1929. doi: 10.1152/japplphysiol.00376.2004

Millet, G. Y., Bachasson, D., Temesi, J., Wuyam, B., Féasson, L., Vergès, S., et al. (2012). Potential interests and limits of magnetic and electrical stimulation techniques to assess neuromuscular fatigue. Neuromuscul. Disord. 22(Suppl. 3), S181-S186. doi: 10.1016/j.nmd.2012.10.007

Millet, G. Y., Martin, V., Lattier, G., and Ballay, Y. (2003). Mechanisms contributing to knee extensor strength loss after prolonged running exercise. J. Appl. Physiol. 94, 193-198. doi: 10.1152/japplphysiol.00600.2002

Millet, G. Y., Martin, V., Martin, A., and Vergès, S. (2011a). Electrical stimulation for testing neuromuscular function: from sport to pathology. Eur. J. Appl. Physiol. 111, 2489-2500. doi: 10.1007/s00421-011-1996-y

Millet, G. Y., Tomazin, K., Verges, S., Vincent, C., Bonnefoy, R., Boisson, R. C., et al. (2011b). Neuromuscular consequences of an extreme mountain ultramarathon. PLoS One 6:e17059. doi: 10.1371/journal.pone.0017059

Miyamoto, N., and Kawakami, Y. (2014). Effect of pressure intensity of compression short-tight on fatigue of thigh muscles. Med. Sci. Sports Exerc. 46, 2168-2174. doi: 10.1249/MSS.0000000000000330

Mizrahi, J., Verbitsky, O., and Isakov, E. (2000). Shock accelerations and attenuation in downhill and level running. Clin. Biomech. 15, 15-20. doi: 10. 1016/S0268-0033(99)00033-9

Mizuno, S., Morii, I., Tsuchiya, Y., and Goto, K. (2016). Wearing compression garment after endurance exercise promotes recovery of exercise performance. Int. J. Sports Med. 37, 870-877. doi: 10.1055/s-0042-106301

Moore, I. S. (2016). Is there an economical running technique? A review of modifiable biomechanical factors affecting running economy. Sports Med. 46, 793-807. doi: 10.1007/s40279-016-0474-4

Morgan, D. L., and Proske, U. (2004). Popping sarcomere hypothesis explains stretch-induced muscle damage. Clin. Exp. Pharmacol. Physiol. 31, 541-545. doi: 10.1111/j.1440-1681.2004.04029.x

Nigg, B. M., and Wakeling, J. M. (2001). Impact forces and muscle tuning: a new paradigm. Exerc. Sport Sci. Rev. 29, 37-41. doi: 10.1097/00003677-20010100000008

Nosaka, K., Newton, M., and Sacco, P. (2002). Delayed-onset muscle soreness does not reflect the magnitude of eccentric exercise-induced muscle damage. Scand. J. Med. Sci. Sports 12, 337-346. doi: 10.1034/j.1600-0838.2002.10178.x

Peake, J. M., Neubauer, O., Della Gatta, P. A., and Nosaka, K. (2017). Muscle damage and inflammation during recovery from exercise. J. Appl. Physiol. 122, 559-570. doi: 10.1152/japplphysiol.00971.2016

Piitulainen, H., Bottas, R., Komi, P., Linnamo, V., and Avela, J. (2010). Impaired action potential conduction at high force levels after eccentric exercise. J. Electromyogr. Kinesiol. 20, 879-887. doi: 10.1016/J.JELEKIN.2009.10.001

Piitulainen, H., Komi, P., Linnamo, V., and Avela, J. (2008). Sarcolemmal excitability as investigated with $\mathrm{M}$-waves after eccentric exercise in humans. J. Electromyogr. Kinesiol. 18, 672-681. doi: 10.1016/j.jelekin.2007.01.004

Place, N., Yamada, T., Bruton, J. D., and Westerblad, H. (2010). Muscle fatigue: from observations in humans to underlying mechanisms studied in intact single muscle fibres. Eur. J. Appl. Physiol. 110, 1-15. doi: 10.1007/s00421-010-1480-0

Proske, U., and Morgan, D. L. (2001). Muscle damage from eccentric exercise: mechanism, mechanical signs, adaptation and clinical applications. J. Physiol. 537, 333-345. doi: 10.1111/j.1469-7793.2001.00333.x

Raastad, T., Owe, S. G., Paulsen, G., Enns, D., Overgaard, K., Crameri, R., et al. (2010). Changes in calpain activity, muscle structure, and function after eccentric exercise. Med. Sci. Sports Exerc. 42, 86-95. doi: 10.1249/MSS. 0b013e3181ac7afa

Saugy, J., Place, N., Millet, G. Y., Degache, F., Schena, F., and Millet, G. P. (2013). Alterations of neuromuscular function after the world's most challenging mountain ultra-marathon. PLoS One 8:e65596. doi: 10.1371/journal.pone. 0065596

Shaw, A. J., Ingham, S. A., and Folland, J. P. (2018). The efficacy of downhill running as a method to enhance running economy in trained distance runners. Eur. J. Sport Sci. 18, 630-638. doi: 10.1080/17461391.2018.1449892

Souron, R., Besson, T., Millet, G. Y., and Lapole, T. (2017). Acute and chronic neuromuscular adaptations to local vibration training. Eur. J. Appl. Physiol. 117, 1939-1964. doi: 10.1007/s00421-017-3688-8

Stickford, A. S. L., Chapman, R. F., Johnston, J. D., and Stager, J. M. (2015). Lower-leg compression, running mechanics, and economy in trained 
distance runners. Int. J. Sports Physiol. Perform. 10, 76-83. doi: 10.1123/ijspp. 2014-0003

Toyomura, J., Mori, H., Tayashiki, K., Yamamoto, M., Kanehisa, H., and Maeo, S. (2017). Efficacy of downhill running training for improving muscular and aerobic performances. Appl. Physiol. Nutr. Metab. 43, 403-410. doi: 10.1139/ apnm-2017-0538

Valle, X., Til, L., Drobnic, F., Turmo, A., Montoro, J. B., Valero, O., et al. (2013). Compression garments to prevent delayed onset muscle soreness in soccer players. Muscles Ligaments Tendons J. 3, 295-302. doi: 10.11138/mltj/2013.3. 4.295

Vercruyssen, F., Easthope, C., Bernard, T., Hausswirth, C., Bieuzen, F., Gruet, M., et al. (2014). The influence of wearing compression stockings on performance indicators and physiological responses following a prolonged trail running exercise. Eur. J. Sport Sci. 14, 144-150. doi: 10.1080/17461391.2012.7 30062

Vercruyssen, F., Gruet, M., Colson, S. S., Ehrstrom, S., and Brisswalter, J. (2017). Compression garments, muscle contractile function, and economy in trail runners. Int. J. Sports Physiol. Perform. 12, 62-68. doi: 10.1123/ijspp.2016-0035

Vernillo, G., Millet, G. P., and Millet, G. Y. (2017). Does the running economy really increase after ultra-marathons? Front. Physiol. 8:783. doi: 10.3389/fphys. 2017.00783

Vernillo, G., Savoldelli, A., Zignoli, A., Skafidas, S., Fornasiero, A., La Torre, A., et al. (2015). Energy cost and kinematics of level, uphill and downhill running: fatigue-induced changes after a mountain ultramarathon. J. Sports Sci. 33, 1998-2005. doi: 10.1080/02640414.2015.1022870

Wakeling, J. M., Von Tscharner, V., Nigg, B. M., and Stergiou, P. (2001). Muscle activity in the leg is tuned in response to ground reaction forces. J. Appl. Physiol. 91, 1307-1317. doi: 10.1152/jappl.2001.91.3.1307

Westerlind, K. C., Byrnes, W. C., and Mazzeo, R. S. (1992). A comparison of the oxygen drift in downhill vs. level running. J. Appl. Physiol. 72, 796-800. doi: 10.1152/jappl.1992.72.2.796

Conflict of Interest Statement: MGi and SC were employed by the Salomon Company, France.

The remaining authors declare that the research was conducted in the absence of any commercial or financial relationships that could be construed as a potential conflict of interest.

Copyright (C) 2018 Ehrstrom, Gruet, Giandolini, Chapuis, Morin and Vercruyssen. This is an open-access article distributed under the terms of the Creative Commons Attribution License (CC BY). The use, distribution or reproduction in other forums is permitted, provided the original author(s) and the copyright owner(s) are credited and that the original publication in this journal is cited, in accordance with accepted academic practice. No use, distribution or reproduction is permitted which does not comply with these terms. 